\title{
Overexpression of AtGRDP2, a novel glycine-rich domain protein, accelerates plant growth and improves stress tolerance
}

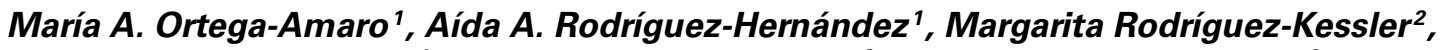 Eloísa Hernández-Lucero' ${ }^{1}$, Sergio Rosales-Mendoza ${ }^{3}$, Alejandro lbáñez-Salazar ${ }^{3}$, Pablo Delgado-Sánchez ${ }^{4}$ and Juan F. Jiménez-Bremont ${ }^{1 *}$}

' División de Biología Molecular, Instituto Potosino de Investigación Científica y Tecnológica AC, San Luis Potosí, México

${ }^{2}$ Facultad de Ciencias, Universidad Autónoma de San Luis Potosí, San Luis Potosi, Mexico

${ }^{3}$ Facultad de Ciencias Químicas, Universidad Autónoma de San Luis Potosí, San Luis Potosi, Mexico

${ }^{4}$ Facultad de Agronomía, Universidad Autónoma de San Luis Potosí, San Luis Potosi, México

\section{Edited by:}

Andrea Pitzschke, University of Natural Resources and Applied Life Sciences (BOKU), Austria

\section{Reviewed by:}

Guillaume Pilot, Virginia Tech, USA Elke Barbez, University of Natural Resources and Applied Life Sciences (BOKU), Austria

${ }^{*}$ Correspondence:

Juan F. Jiménez-Bremont, División de Biología Molecular, Instituto

Potosino de Investigación Científica y Tecnológica AC, Camino a la Presa de San José 2055, C.P. 78216, AP 3-74 Tangamanga, San Luis Potosí, México

e-mail: jbremont@ipicyt.edu.mx
Proteins with glycine-rich signatures have been reported in a wide variety of organisms including plants, mammalians, fungi, and bacteria. Plant glycine-rich protein genes exhibit developmental and tissue-specific expression patterns. Herein, we present the characterization of the AtGRDP2 gene using Arabidopsis null and knockdown mutants and, Arabidopsis and lettuce over-expression lines. AtGRDP2 encodes a short glycine-rich domain protein, containing a DUF1399 domain and a putative RNA recognition motif (RRM). AtGRDP2 transcript is mainly expressed in Arabidopsis floral organs, and its deregulation in Arabidopsis Atgrdp2 mutants and 35S::AtGRDP2 over-expression lines produces alterations in development. The 35S::AtGRDP2 over-expression lines grow faster than the WT, while the Atgrdp2 mutants have a delay in growth and development. The over-expression lines accumulate higher levels of indole-3-acetic acid and, have alterations in the expression pattern of ARF6, ARF8, and miR167 regulators of floral development and auxin signaling. Under salt stress conditions, 35S::AtGRDP2 over-expression lines displayed higher tolerance and increased expression of stress marker genes. Likewise, transgenic lettuce plants over-expressing the AtGRDP2 gene manifest increased growth rate and early flowering time. Our data reveal an important role for AtGRDP2 in Arabidopsis development and stress response, and suggest a connection between AtGRDP2 and auxin signaling.

Keywords: glycine-rich domain protein, Arabidopsis thaliana, Lactuca sativa, development, indole-3-acetic acid, salt stress

\section{INTRODUCTION}

Glycine-rich proteins (GRPs) are characterized by a high content of glycine (40-70\%) and repetitive sequence of residues arranged in (Gly) $)_{\mathrm{n}}$-X motifs (Sachetto-Martins et al., 2000; Mousavi and Hotta, 2005). Proteins with particular glycine-rich regions have been reported in a wide variety of organisms including plants (Sachetto-Martins et al., 2000). Plant GRP genes exhibit developmentally regulated and tissue-specific expression patterns; these patterns are also regulated by abiotic and biotic factors (SachettoMartins et al., 2000).

The plant GRP family is classified according to its general structure. Currently, five groups have been suggested, according to the arrangement of the repeated glycine signatures as well as the presence of conserved motifs and domains (SachettoMartins et al., 2000; Mangeon et al., 2010). The first three classes and the fifth are based on the arrangement of the glycinerich domain, i.e., (I) GGX, (II) GGXXXGG, (III) GXGX, and (V) GGX/GXGX, respectively; they also contain a signal peptide, oleosin, or cysteine-rich domain. The group IV is based on the presence of additional motifs and domains such as RNA recognition motif (RRM), cold shock and zinc finger domains, and a cysteine-rich domain, among others (Bocca et al., 2005; Mangeon et al., 2010). Until now, few plant GRPs have been characterized; these proteins appear to play important roles in transcriptional regulation, signal transduction, protein-protein interaction, development, and stress responses (Bocca et al., 2005).

GRPs are involved in developmental processes in plants. The bean PvGRP1.8 has been proposed to act as an agglutinating agent for deposition of cell wall constituents (Keller et al., 1988) and it has been associated with protoxylem growth (Ryser et al., 1997). In stems and leaves of Petunia plants, the levels of PtGRP1 gene decline with the developmental age of the tissue. In particular, PtGRP1 gene expression levels were associated to expansive growth, and the PtGRP1 protein was localized in the cell wall/membrane interphase (Condit, 1993). In the past years, it has been documented that some plant hormones that regulate many aspects of plant growth, development and stress responses 
modulate the expression of GRP genes (Reddy and Poovaiah, 1987; Urbez et al., 2006; Long et al., 2013).

In addition to the canonical GRPs, Bocca et al. (2005) reported the presence of glycine-rich domain proteins (GRDPs) transcripts in Eucalyptus, which encode proteins with a short glycine-rich domain. Recently, we reported the AtGRDP1 gene, encoding a short glycine-rich domain protein, which plays a regulatory role in ABA signaling and abiotic stress tolerance (RodríguezHernández et al., 2014).

To deepen our understanding in GRDPs, herein we present the characterization of AtGRDP2 gene, paralog of AtGRDP1. Arabidopsis plants that overexpress the AtGRDP2 gene were obtained. These plants grow faster and flower earlier than the WT, while Atgrdp2 knockout and knockdown mutants have a delay in growth and development. The over-expression of AtGRDP2 in lettuce plants also conduces to increased growth rate and early flowering time. In Arabidopsis, AtGRDP2 gene is highly expressed in floral organs, and is auxin-responsive. We further show that 35S::AtGRDP2 overexpression lines accumulate higher levels of indole-3-acetic acid, which might explain their fast growth. We analyzed central regulators in auxin signaling such as $A R F 2$, ARF6, ARF8, AUX1, and miR167, and found that these genes are differentially expressed in Atgrdp2-1 mutant and 35S::AtGRDP2 overexpression lines. Under salt stress conditions, seedlings of 35S::AtGRDP2 lines displayed higher tolerance and increased expression of stress marker genes. Our data reveal an important role for AtGRDP2 in Arabidopsis development and stress responses, possibly through an auxin-dependent mechanism.

\section{MATERIALS AND METHODS PLANT MATERIAL AND GROWTH CONDITIONS}

The mutant and transgenic lines used in this study were generated in the Arabidopsis thaliana ecotype Columbia 0 (Col-0) background. Arabidopsis seeds of each line were surface-sterilized for 10 min with $40 \%(\mathrm{v} / \mathrm{v})$ chlorine solution and rinsed six times in sterile distilled water. Aseptic stratified seeds ( 2 days at $4^{\circ} \mathrm{C}$ ), were germinated and grown on agar plates containing $0.5 \mathrm{x}$ Murashige and Skoog (MS) medium, pH 5.7, 0.5\% (w/v) sucrose, and $1.2 \%$ $(\mathrm{w} / \mathrm{v})$ agar (Murashige and Skoog, 1962). Plates were incubated in a growth chamber with a photoperiod of $16 \mathrm{~h}$ (13,000 luxes) / $8 \mathrm{~h}$, light/dark cycle at a temperature of $22 \pm 2{ }^{\circ} \mathrm{C}$. Plants were grown in plastic pots with a mixture of Sunshine Mix\#3 commercial substrate and vermiculite (3:1), under environmental controlled conditions.

Seeds of Lactuca sativa L. (WT) and seeds of 35S::AtGRDP2 transgenic lettuce plants were sterilized with $20 \%$ (v/v) chlorine solution for $10 \mathrm{~min}$, and rinsed five times in sterile distilled water. Aseptic seeds were germinated in Petri dishes containing $0.5 \mathrm{x}$ MS medium. Plates were kept at $4^{\circ} \mathrm{C}$ for 2 days and then incubated at $22 \pm 2^{\circ} \mathrm{C}$ for 7 days in a growth chamber under a $16 \mathrm{~h}$ light $/ 8 \mathrm{~h}$ dark photoperiod. Afterwards, plants were transferred to soil pots in a growth chamber at $25 \pm 2{ }^{\circ} \mathrm{C}$ with a $16 \mathrm{~h}$ light $/ 8 \mathrm{~h}$ dark photoperiod.

\section{IDENTIFICATION OF THE T-DNA INSERTIONAL MUTANT LINE (Atgrdp2-1)}

The T-DNA mutant line Sail_387_D04 for the AtGRDP2 gene (At4g37900) was acquired from the Salk Institute Genome
Analysis Laboratory (www.signal.salk.edu/cgi-bin/tdnaexpress; Alonso et al., 2003). Absence of AtGRDP2 expression in TDNA mutant line was confirmed by semi-quantitative RT-PCR using the Sail387D04-F and Sail387D04-R primers (Table S1). cDNA synthesis was carried out using $1 \mu \mathrm{g}$ of total RNA and the SuperScript ${ }^{\mathrm{TM}}$ First-Strand Synthesis System (Invitrogen). The Actin 8 gene (Atlg49240) was amplified as loading control using the ACT8-F and ACT8-R primers (Table S1).

\section{VECTORS FOR AtGRDP2 OVEREXPRESSION AND GENE SILENCING}

AtGRDP2 ORF was amplified from cDNA of 15 day-old Arabidopsis plants with Hot Star HiFidelity Polymerase Kit (Qiagen, Hilden, Germany) using the primers: AtGRDP2-ORF$\mathrm{F}$ and AtGRDP2-ORF-R primers (Table S1). The product of $2377 \mathrm{bp}$ was cloned into the $\mathrm{pCR} 8 / \mathrm{GW} / \mathrm{TOPO}$ vector (Invitrogen, Carlsbad, CA, USA), and was sequenced using the M13-F and AtGRDP2-ORF-R primers. The entry clone was recombined into the destination vector pMDC32 using the Gateway LR Clonase Enzyme mix (Invitrogen) to generate pMDC32-GRDP2 vector.

To silence the AtGRDP2 gene, an artificial miRNA $p A m i R$ AtGRDP2 vector from Thermo Fisher Scientific Inc. was acquired (Waltham, MA, USA). This vector contains 27 bp of the AtGRDP2 gene between the miR319a harpin sequence embedded in their genomic context, $35 \mathrm{~S}$ CaMV promoter, and the BASTA resistance (Schwab et al., 2006).

\section{TRANSFORMATION OF ARABIDOPSIS AND LETTUCE}

The vectors $p M D C 32-G R D P 2$ and $p A m i R-A t G R D P 2$ were transferred into Agrobacterium tumefaciens GV2260 strain by electroporation, and transformed into $A$. thaliana Col-0 plants by the floral dip method (Clough and Bent, 1998). Afterwards, seeds were harvested for selection under a specific plant selection marker. Hygromycin was used at $50 \mu \mathrm{g} / \mathrm{mL}$ for $p M D C 32-G R D P 2$ selection. Ten independent 35S::AtGRDP2 lines were obtained, and four T3 homozygous lines were used for further analysis. For $p A m i R-A t G R D P 2$ selection, 1-week-old germinated seedlings were sprayed using a $0.25 \mathrm{~g} / \mathrm{L}$ BASTA (Finale ${ }^{\circledR}$, Bayer Cropscience, Monheim, Germany). Five independent amiR-AtGRDP2 T3 homozygous lines were obtained.

Lettuce plants carrying the AtGRDP2 gene were generated by Agrobacterium-mediated transformation, following Curtis et al. (1994) method with some modifications (Martinez-Gonzalez et al., 2011). Nine lettuce transgenic lines were obtained in F1 generation, and the presence of the transgene was confirmed by PCR. T3 homozygous seedlings of three transgenic plants were used for further analysis.

\section{QUANTITATIVE RT-PCR (qRT-PCR) OF AtGRDP2 GENE IN ARABIDOPSIS Col-O PLANTS}

Total RNA was obtained from different tissues of 18, 21, 26, 28, and 45 days old $A$. thaliana Col-0 plants. AtGRDP2 expression levels were estimated by qRT-PCR as described below using the following primers: AtGRDP2-F and AtGRDP2-R (Table S1). For each tissue, three biological replicates were analyzed with their respective technical replicates. Each biological replicate consisted in groups of 10 seedlings. 


\section{EXPRESSION ANALYSIS OF MUTANT AND OVEREXPRESSION LINES BY qRT-PCR}

Arabidopsis RNA extractions were done with 100-200 mg of plant material following the Concert ${ }^{\mathrm{TM}}$ Plant RNA Reagent protocol (Invitrogen). Each mRNA biological replicate consisted in groups of 10 plants per line. Contamination of genomic DNA was eliminated by treatment with DNase I (Invitrogen). AtGRDP2 expression levels in Arabidopsis amiR and 35S::AtGRDP2 overexpression lines was estimated from 15 days old plants, using the primers: AtGRDP2-F and AtGRDP2-R (Table S1). cDNA synthesis and quantitative PCR analyses were done in a $10 \mu \mathrm{L}$ reaction mixture containing $50 \mathrm{ng}$ of total RNA as template using the Power SYBR ${ }^{\circledR}$ Green RNA-to-CT ${ }^{\mathrm{TM}}$ One-Step Kit (Applied Biosystems). The thermal cycling conditions consisted of $30 \mathrm{~min}$ at $48^{\circ} \mathrm{C}$ (cDNA synthesis), $10 \mathrm{~min}$ at $95^{\circ} \mathrm{C}$ (activation of AmpliTaq Gold ${ }^{\circledR}$ DNA polymerase), followed by 40 PCR cycles of $15 \mathrm{~s}$ at $95^{\circ} \mathrm{C}$ (denature) and $1 \mathrm{~min}$ at $60^{\circ} \mathrm{C}$ (anneal/extend). Melting curves were performed by cycles of $15 \mathrm{~s}$ at $95^{\circ} \mathrm{C}$ (denature), 15 at $60^{\circ} \mathrm{C}$ (anneal) and $15 \mathrm{~s}$ at $95^{\circ} \mathrm{C}$ (denature), increasing the temperature each $0.3^{\circ} \mathrm{C}$. The cycle number at threshold $(\mathrm{Ct}$ value) was used for calculations of relative mRNA expression levels. The Ct value of each target gene was normalized by subtraction of the Ct value from the Arabidopsis ubiquitin 5 (At3g62250) gene. The fold change in gene expression relative to control samples (Col-0) was calculated using the $2^{-\Delta \Delta \mathrm{Ct}}$ method (Livak and Schmittgen, 2001). For each sample, three biological replicates were analyzed with their respective technical replicates.

Lettuce RNA extractions were done with 100-200 mg of plant material following the Concert ${ }^{\mathrm{TM}}$ Plant RNA Reagent protocol (Invitrogen). Contamination of genomic DNA was eliminated by treatment with DNase I (Invitrogen). AtGRDP2 expression levels in transgenic lettuce were also estimated from 15 days old plants, using the AtGRDP2-F and AtGRDP2-R primers (Table $\mathrm{S} 1)$. Relative gene expression levels of AtGRDP2 gene in transgenic lettuce are presented as $2^{-\Delta \mathrm{Ct}}$, where $\Delta \mathrm{Ct}=\mathrm{Ct}_{A t G R D P 2}-$ $\mathrm{Ct}_{L s U B Q 5}$. For the amplification of the lettuce $L s U B Q 5$ gene, the LsUBQ5-F and LsUBQ5-Rv primers were used (Table S1). For each sample, three biological replicates were analyzed with their respective technical replicates.

\section{ANALYSIS OF AtGRDP2 PROMOTER::GUS-GFP EXPRESSION}

The AtGRDP2 promoter region (2 kb upstream of the start codon) was PCR-amplified from the Arabidopsis genomic DNA. Amplification was carried out with primers ATPROM37fw and ATPROM37rv (Table S1). The fragment was cloned into $\mathrm{pCR}^{\circledR} 8 / \mathrm{GW} / \mathrm{TOPO}^{\circledR}{ }^{\circledR}$ entry vector (Invitrogen) and fused by recombination to the GUS-GFP reporter genes in the pKGWFS7 binary vector (Karimi et al., 2002). Agrobacterium tumefaciens GV2260 strain harboring the AtGRDP2 promoter::GUSGFP construction was used for Arabidopsis transformation, as described before. Five independent transgenic lines were selected on $50 \mu \mathrm{g} / \mathrm{mL}$ kanamycin. T3 homozygous seedlings were used for GUS histochemical analysis as described below.

\section{HISTOCHEMICAL ANALYSIS IN ARABIDOPSIS pAtGRDP2::GUS-GFP REPORTER LINES}

Expression patterns of the 45 day-old Arabidopsis pAtGRDP2::GUS-GFP reporter lines were analyzed. For GUS staining, two independent lines ( $p A t G R D P 2:: G U S-G F P-1$ and pAtGRDP2::GUS-GFP-2) were used, following the protocol described previously (Ortega-Amaro et al., 2012). For each marker line, 10 transgenic plants were analyzed. A representative plant was chosen and photographed using MOTIC model BA-300 microscope and processed with MOTIC software (version 2.0) using a 5.0 megapixels camera. The anatomy of Arabidopsis flower was described according to Roeder and Yanofsky (2006). All experiments were repeated at least twice obtaining similar results.

\section{MEASUREMENT OF FLOWERING TIME}

Flowering time in Arabidopsis in both short $(8 \mathrm{~h} / 16 \mathrm{~h}$ light/dark cycle) and long (16 h/8 h light/dark cycle) day conditions was estimated by recording the number of days after sowing in which the inflorescence reached $1 \mathrm{~cm}$ in length; in addition, at the same time the rosette leaves were counted. Flowering time in lettuce plants was recorded daily as of the appearance of the floral bud, and data were graphically represented as the percentage of plants with floral tissues.

\section{HISTOCHEMICAL ANALYSIS IN ARABIDOPSIS pATGRDP2::GFP-GUS LINES UNDER IAA TREATMENTS}

Seven day-old pAtGRDP2::GFP-GUS-1 and pAtGRDP2::GFPGUS-2 seedlings grown in $0.5 \mathrm{x}$ MS plates were transferred to $0.5 \mathrm{x}$ MS liquid medium supplemented with 0,1 , and $10 \mu \mathrm{M}$ IAA and, incubated for 3 and $6 \mathrm{~h}$ in a grown chamber under controlled conditions.

For each marker line and for each treatment, 10 transgenic plants with three replicates were analyzed. After each treatment, seedlings were subjected to GUS histochemical analysis as described before. Images of pAtGRDP2::GFP-GUS-1 and pAtGRDP2::GFP-GUS-2 lines were recorded. A representative plant was chosen and photographed using Leica microscope at $10 \mathrm{X}$ magnification and recorded using the Leica Application Suite 3.0.0 software.

\section{IAA CONTENT ON ARABIDOPSIS BY ELISA ASSAY}

For IAA estimation 30 day-old A. thaliana Col-0, Atgrdp2-1, and amiR-1 mutants and AtGRDP2 over-expression lines were used. The extract was obtained from $1 \mathrm{~g}$ of ground plant tissue, and incubated overnight in $80 \%$ methanol at $4^{\circ} \mathrm{C}$. Methyl groups were added by the addition of $1.3 \mu \mathrm{l}$ trimethylsilyldiazomethane. Next, the samples and the IAA standard were processed by the manufacturer's protocol (Phytodetek ${ }^{\circledR}$ IAA Test Kit, Agdia, USA). Absorbance values at $405 \mathrm{~nm}$ were obtained using a BioTek ELx800 microplate reader, and then the concentration of IAA was calculated based on standard curve. Standard curve and IAA estimation in Arabidopsis extracts (1:20 dilution) were performed on three biological replicates with their respective technical replicates.

\section{EXPRESSION OF AUXIN RELATED GENES IN ARABIDOPSIS}

The expression level of auxin related genes in the Col-0, Atgrdp21, and 35S::AtGRDP2-OE3 overexpression lines was analyzed by qRT-PCR. The auxin related genes ARF6 (At1g30330), ARF8 (At5g37020), ARF2 (At5g62000), AUX1 (At2g38120) were measured in 21 days old plants. For the estimation of miR167 
(At3g04765) expression levels, $1 \mu \mathrm{g}$ of total RNA was used for small RNA polyadenylation process and CDNA production following the NCode miRNA cDNA synthesis kit (Invitrogen) manufacture directions. qPCR was performed with SYBR Green qPCR Master Mix (Thermo scientific) protocol. Quantitation was based on a cycle threshold value (Livak and Schmittgen, 2001). Specific primers for each gene are indicated in table S1. For each sample, three biological replicates were analyzed with their respective technical replicates. Each biological replicate consisted in groups of 10 seedlings. In case of ratios lower than 1, the inverse of the ratio was estimated and the sign was changed.

\section{MEASUREMENT OF MAIN ROOT SIZE AND FRESH WEIGHT OF SEEDLINGS}

A. thaliana seeds of the Col-0, the Atgrdp2-1 and amiR-1 mutants, and the 35S::AtGRDP2 overexpression lines were grown on $0.5 \mathrm{x}$ MS plates for 14 days. Estimation of main root size $(\mathrm{cm})$ was determined by measuring the length of 30 plant roots of each line. Fresh weight $(\mathrm{mg})$ of seedlings was obtained on an analytical scale and the values obtained represent means of three groups of 10 seedlings for line. Estimation of lettuce (WT and transgenic plants) main root size $(\mathrm{cm})$, stem length $(\mathrm{cm})$ and fresh weight (mg) was obtained from 9 seedlings of each line. Statistical significance among data was estimated by One-way-ANOVA and Tukey's multiple comparison post-test, using GraphPad Prism version 5.0 (GraphPad Software, California, USA). The experiment was repeated three times with similar results.

\section{ARABIDOPSIS SALINITY STRESS ASSAY IN VITRO}

Fourteen days-old Arabidopsis Col-0, Atgrdp2-1 and overexpression lines (35S::AtGRDP2) grown on MS $0.5 \mathrm{x}$, were transferred into $0.5 \mathrm{x}$ MS plates supplemented with 0 or $150 \mathrm{mM} \mathrm{NaCl}$. After 7 days of stress, the main root size of untreated and treated plantlets was estimated measuring 30 roots of each line. The relative root length was calculated (treated with $150 \mathrm{mM} \mathrm{NaCl} /$ untreated). Fresh weight $(\mathrm{mg})$ of seedlings was obtained on an analytical scale and the values obtained represent means of three groups of 10 seedlings of each line. The relative fresh weight was calculated (treated with $150 \mathrm{mM} \mathrm{NaCl}$ /untreated). After 7 days of salt stress, groups of 10 seedlings of each line were transferred to three pots with soil mixture substrate, grown under controlled conditions $\left(22 \pm 2{ }^{\circ} \mathrm{C} ; 16 \mathrm{~h}\right.$ light $/ 8 \mathrm{~h}$ dark photoperiod) and irrigated every 3 days, to observe post-stress recovery. Plant survival rate was calculated by counting the number of plants that survived in each pot, after a period of 14 days. The experiment was repeated three times with similar results.

\section{LETTUCE SALINITY STRESS ASSAY IN VITRO}

Lettuce seeds of WT and transgenic plants were germinated on MS medium supplemented with 0 and $150 \mathrm{mM} \mathrm{NaCl}$. After 21 days of treatment, data of root length and fresh weight were recorded. Estimation of lettuce (WT and transgenic plants) main root length and fresh weight was obtained from 9 seedlings of each line. The relative root length was calculated (treated with $150 \mathrm{mM} \mathrm{NaCl} /$ untreated). These stress experiments were repeated three times obtaining similar results.

\section{EXPRESSION OF SALT STRESS RELATED GENES IN ARABIDOPSIS}

Fourteen days old Col-0, Atgrdp2-1 and 35S::AtGRDP2-OE3 overexpression line, grown on $0.5 \mathrm{x}$ MS plates were used. Ten seedlings of each line in triplicate manner were transferred to $0.5 \mathrm{x}$ MS medium with 0,125 , and $150 \mathrm{mM} \mathrm{NaCl}$ and, incubated for 1 and 3 days in a growth chamber under controlled conditions. After, plantlets of each treatment were frozen in liquid nitrogen and total RNA extraction was performed as described before. RNA was used for expression analysis of RD29B (At5g52300), EM6 (At2g40170), and ABF4 (At3g1929) genes by qRT-PCR. Specific primers are indicated in Table S1. For each sample, three biological replicates were analyzed with their respective technical replicates. Each biological replicate consisted of groups of 10 seedlings. In case of ratios lower than 1 , the inverse of the ratio was estimated and the sign was changed.

\section{MEASUREMENT OF CHLOROPHYLL AND CAROTENOIDS CONTENT IN LETTUCE PLANTS}

The chlorophylls $a, b$, total chlorophyll, and carotenoids contents were obtained from 30, 60, and 90 days old WT and transgenic lettuce plants. Three samples (leaf disc) of four plants of each line were collected. The pigments were extracted according to the procedure of Hendry and Price (1993). Samples of $50 \mathrm{mg}$ fresh weight were macerated with $1 \mathrm{~mL} 80 \%$ acetone. These samples were centrifuged at $3000 \mathrm{~g}$ for $2 \mathrm{~min}$ and the absorbance of each supernatant was determined with the following wavelengths: 645 and $663 \mathrm{~nm}$ for chlorophylls $a$ and $b$, and at $470 \mathrm{~nm}$ for total carotenoids, using a spectrophotometer (Thermo Scientific ${ }^{\circledR}$, Model Spectronic Genesys 10 Bio).

\section{SEQUENCE ANALYSIS}

Comparisons and protein sequence alignments were carried out using the CLUSTAL $\mathrm{W}$ and the T-Coffee programs at the EBI database (www.ebi.ac.uk). The amino acid sequences of the AtGRDP2 (At4g37900) protein and selected plant orthologous and $A$. thaliana paralogous proteins containing the DUF1399 domain were aligned using the T-Coffee Multiple Sequence Alignment Tool of the EBI database using default values (Notredame et al., 2000). The aligned sequences were subjected to re-sampling with replacement (1000 bootstrap) using the Seqboot program and subsequently analyzed by a distance method in the PHYLIP 3.67 package (Felsenstein, 1989). The distance matrix was calculated with the Protdist program using the Henikoff/Tillier Probability Matrix from Blocks (PMB, Veerassamy et al., 2003). The resultant matrices were then transformed into multiple trees by the Neighbor Joining program and summarized by the program Consense (both programs of the PHYLIP 3.67 package) (Felsenstein, 1989). The majority rule consensus tree was edited with the MEGA version 5.0 program (Tamura et al., 2011).

\section{RESULTS}

\section{ARABIDOPSIS AtGRDP2 GENE ENCODES A GLYCINE-RICH DOMAIN} PROTEIN

The AtGRDP2 (Arabidopsis thaliana glycine-rich domain protein 2) gene encodes a glycine-rich domain protein. The AtGRDP2 (At4g37900) gene is located in chromosome 4, and its genomic 
organization consists of five exons and four introns. The AtGRDP2 cDNA is 2428 bp in length containing an open reading frame (ORF) of $2364 \mathrm{pb}$ that encodes a protein of 787 aa. Protein sequence analyses revealed a domain of unknown function (DUF1399), a putative RNA binding motif (RNP), and a glycine-rich domain (GRD) in the AtGRDP2 protein (Figure S1A). The DUF1399 domain is located in the N-terminus and consists of 142 aa. The putative RNA binding motif (KGSCFLPM) is placed in the central region of the protein, and it is equivalent to RNP-1 (ribonucleoprotein-1) present in proteins with RNA chaperone activity (Lorković and Barta, 2002). The glycine-rich domain is found in the C-terminus (aa 713-766); this domain also contains interspersed cysteine residues (Figure S1A). Comparison of phylogenetically related GRDPs reveals that the three domains found in AtGRDP2 are conserved in the orthologous proteins analyzed (Figures S1, S2). AtGRDP2 is grouped with orthologous GRDPs of dicot plants (Figure S1B), mainly with proteins from the Brassicaceae species. A consensus glycine region [CG]GGGCGG[GC], elucidated by MEME program (Bailey and Elkan, 1994), was identified among the AtGRDP2 orthologs (Figures S1A, S2).

In the A. thaliana genome, in addition to AtGRDP2, we have identified three additional genes encoding proteins that also contain the DUF1399 domain, named AtGRDP1 (RodríguezHernández et al., 2014), Atlg56230, and At4g37682. The AtGRDP1 protein also contains the RNP-1 and glycine richregion domains, while the At1g56230 and At4g37682 encoded proteins lack these domains (Figure S1C).

\section{AtGRDP2 IS EXPRESSED THROUGHOUT ARABIDOPSIS DEVELOPMENT}

AtGRDP2 tissue-specific expression pattern was evaluated by qRT-PCR at different developmental stages, in A. thaliana ecotype Col-0 plants of 18, 21, 26, 28, and 45 days old (Figures 1A,B). The highest AtGRDP2 expression levels were found in rosette leaves, in inflorescence tissues such as cauline leaves, buds, flowers, and in immature siliques (Figure 1A). In rosette and cauline leaves, the highest expression was detected in 28-day-old plants. In flowers, the maximum expression of AtGRDP2 was noticed at day 45; although expression in buds and flowers was detected as of day 26. Furthermore, AtGRDP2 gene expression was maintained in immature siliques, but expression fell toward baseline values in mature siliques (Figure 1A).

AtGRDP2 expression in floral tissues was also evaluated using Arabidopsis reporter lines expressing the GFP-GUS fusion under the control of the AtGRDP2 promoter (2000 bp) (Figure 1C). GUS histochemical assays confirmed AtGRDP2 expression in flower organs and immature siliques (Figure 1C). GUS expression was detected on the stigmas $(\mathrm{St})$, at the top of the ovary $(\mathrm{Ov})$, internode region (I), and in floral buds and fertilized siliques (Fs).

\section{AtGRDP2 GENE IS INVOLVED IN ARABIDOPSIS DEVELOPMENT}

To address the biological functions of AtGRDP2 gene in plant growth and development, mutant and over-expression lines were characterized. The T-DNA homozygous line (Sail_387D04) was analyzed for the absence of AtGRDP2 transcript, confirming that the Sail_387D04 line is a null allele (Figure S3). The amiRAtGRDP2-1 line (-1.7-fold repression), and four Arabidopsis lines over-expressing the AtGRDP2 gene (35S::AtGRDP2-OE2 4.8-fold, -OE4 21.6-fold, -OE1 102.6-fold, and -OE3 451.3-fold) were selected for subsequent analyses (Figure S3D).

Growth rate was evaluated in 2-week-old Arabidopsis Atgrdp2 mutants and AtGRDP2 over-expression lines. At this stage, seedlings of knockout and knockdown lines exhibited smaller sizes than those of WT plantlets (Figure 2A), reflected in their root length and fresh weight (Figures 2B,C). Interestingly, the AtGRDP2 over-expression lines presented an opposite phenotype, resulting in a higher growth rate in comparison to WT seedlings, in both the aerial part and the roots (Figure 2A). The increased growth rate observed in 35S::AtGRDP2-OE3 plantlets could be attributed to a higher accumulation of AtGRDP2 transcript in this line (Figure S3). Since deregulation of AtGRDP2 gene results in plant growth alterations, we analyzed the flowering time under long- and short-day conditions (Figures 2D-I). In long-day conditions, AtGRDP2 over-expression lines showed faster development and early flowering in comparison with the WT (Figures 2D,E). Instead, the knockout and knockdown lines showed late flowering phenotype (Figures 2D,E). At day 34, the percentages of plants with inflorescences were as follows: $>80 \%$ in the AtGRDP2 over-expression lines, $66 \%$ in the WT, $46.6 \%$ in the knockdown line and $40 \%$ in the knockout line. Regarding the number of rosette leaves, no significant differences were observed in most of the analyzed lines. The exception was in the 35S::AtGRDP2-OE1 which had more rosette leaves (Figure 2F).

Flowering time experiments under short-day conditions exhibited similar behavior to that observed in plants grown in long-days. The AtGRDP2 over-expression lines showed early flowering in comparison with WT plants, knockout and knockdown lines (Figures 2G-I). Finally, no differences in the number of rosette leaves at the flowering time were found between WT and the analyzed lines (Figure 2I).

All previous experiments showed that the Atgrdp2-1 and amiR-1 lines have a delay in development; it might be possible that hormonal pathways controlling development are affected. Interestingly, Goda et al. (2004) reported that the AtGRDP2 belongs to a group of genes specifically regulated by indole3 -acetic acid (IAA). We analyzed IAA levels in WT, mutant and overexpression lines (Figure 3A), and we observed that the 35S::AtGRDP2-OE2 and -OE4 over-expression lines accumulated the highest IAA levels (Figure 3A). Furthermore, the effect of auxins on AtGRDP2 gene expression was evaluated in the pAtGRDP2::GFP-GUS-1 reporter line. GUS histochemical analyses were carried out in 7 day-old pAtGRDP2::GFP-GUS-1 and -2 transgenic lines treated with 0,1 , and $10 \mu \mathrm{M}$ IAA for 3 and $6 \mathrm{~h}$ (Figure 3B). Plant treatments with IAA show increases in GUS signal in the root-hypocotyl junction (collet), and in the root differentiation zone in comparison to non-treated plants. In addition, IAA induces GUS signal in the root elongation zone; however, no signal is detected in root meristematic zone in control and treated seedlings (Figure 3B).

AtGRDP2 appears to be an auxin-regulated gene, and the difference in IAA concentrations might be responsible for the accelerated growth rate phenotype observed in AtGRDP2 
overexpression lines. The relation between auxins and AtGRDP2 gene was also explored by measuring the expression of Auxin Response Factors (ARF2, ARF6, ARF8), miR167, and the auxin transporter $A U X 1$ by qRT-PCR. Interestingly, the ARF6, ARF8, and AUX1 genes are induced in the 35S::AtGRDP2-OE3 line and repressed in the Atgrdp2-1 mutant (Figure 3C); opposite to ARF2 which is induced in the Atgrdp2-1 line. The miR167, which is a negative regulator of ARF6 and ARF8

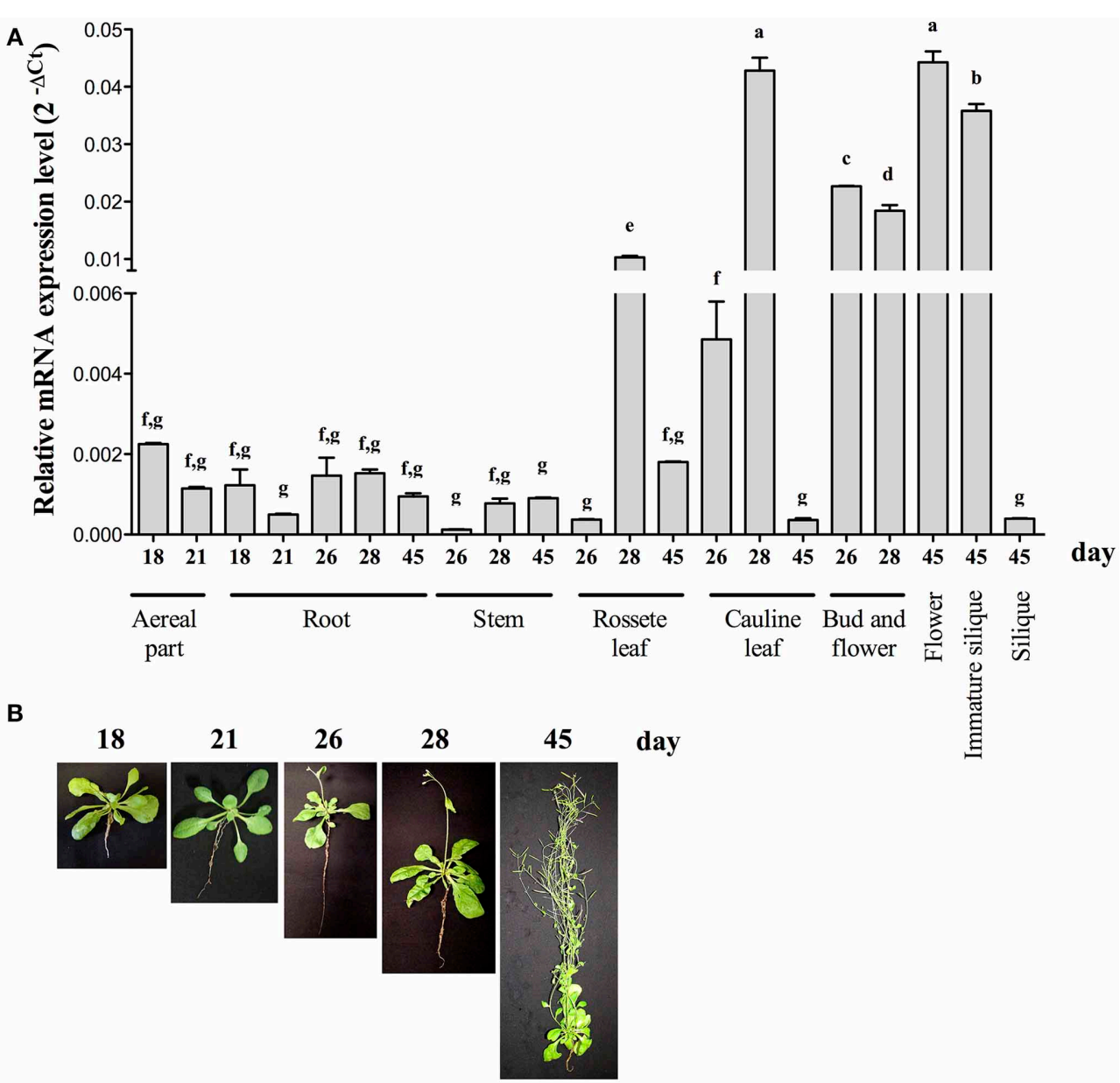

C

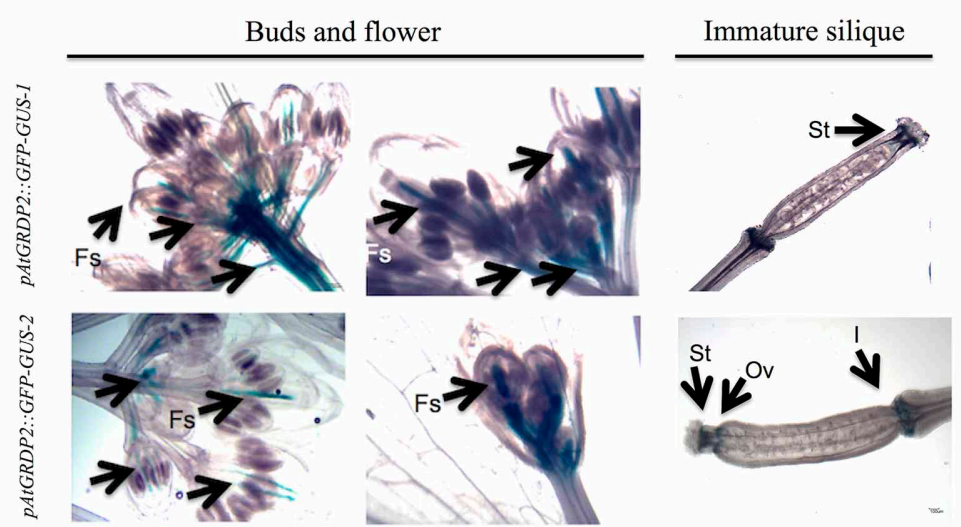

FIGURE 1 |AtGRDP2 is expressed throughout Arabidopsis development. (A) qRT-PCR analysis was performed in Arabidopsis Col-0 tissues obtained from different developmental stages. Quantitation of the AtGRDP2 gene, expressed as relative mRNA expression levels $\left(2^{-\Delta \mathrm{Ct}}\right)$, was calculated after normalization to the Arabidopsis UBO5 gene. For each sample, three biological replicates were analyzed with their respective technical replicates. Letters indicate significant differences between samples according to Tukey's multiple comparison tests at $P<0.05$. (B) Photographs show representative Arabidopsis plant at 18,21, 26, 28 and 45 days. (C) Representative images of GUS histochemical staining of 45 day-old transgenic lines AtGRDP2::GFP-GUS-1 and -2 in buds, flowers and immature siliques; fertilized siliques (Fs), stigmas (St), internode region (I), and ovary (Ov) are indicated. 

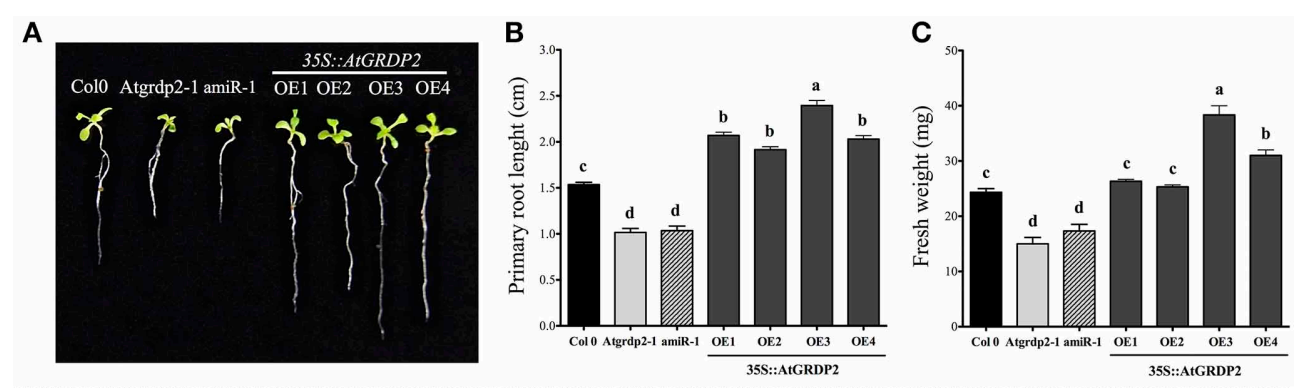

D

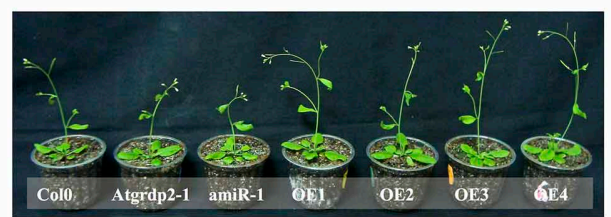

E

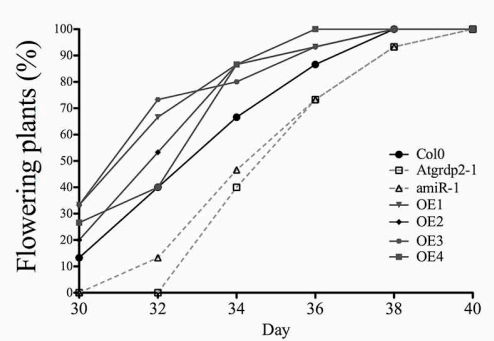

F

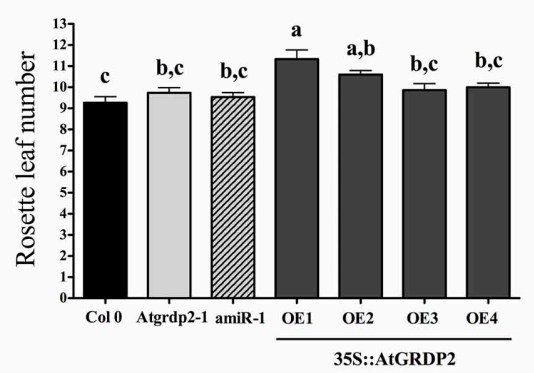

FIGURE 2 | Growth of Col-0, Atgrdp2-1, amiR-1, and AtGRDP2 overexpression lines. (A) Phenotype of 14-day-old WT, mutants and overexpression seedlings. Primary root length (B) and fresh weight (C) were measured. Estimation of main root length $(\mathrm{cm})$ was determined by measuring the length of 30 plant roots of each line. The fresh weight $(\mathrm{mg})$ of the seedlings was obtained on an analytical scale and the values obtained represent the means of three groups of 10 seedlings of each line. Estimation of flowering time in plants grown under long days. (D) Phenotype of 40
G

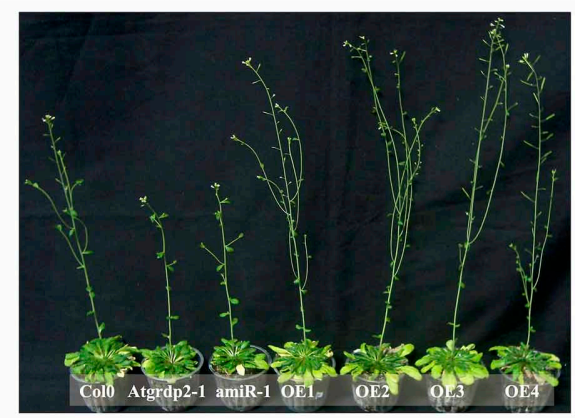

H

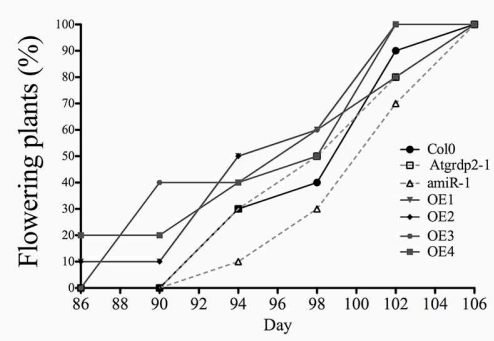

I

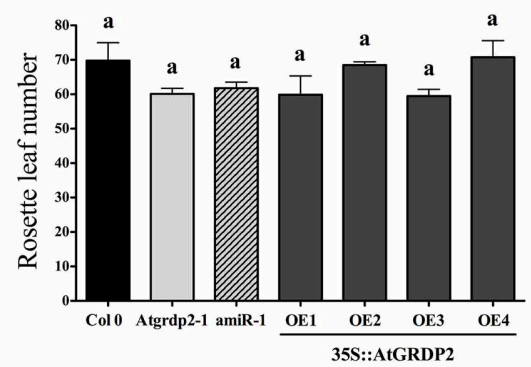

day-old plants, (E) distribution of flowering plants, and (F) rosette leaf number in Col-0, mutant, and over-expression lines (mean \pm SE $n=15$ ). Estimation of flowering time in plants grown under short days. (G) Phenotype of 110 day-old plants, (H) distribution of flowering plants and (I) rosette leaf number in Col-0, mutant and over-expressing lines (mean \pm SE $n=15$ ). Error bars denote SE and significant differences are indicated with different letters. One-Way ANOVA was used to analyze the data $(P<0.05)$ and differences among treatments were explored through Tukey's multiple comparisons tests. transcription factors, was found up-regulated in the Atgrdp2 mutant, and decreased in 35S::AtGRDP2 overexpression line (Figure 3C).

\section{OVEREXPRESSION OF ATGRDP2 IN ARABIDOPSIS IMPROVES RECOVERY AFTER SALT STRESS}

Two-week old Arabidopsis Col-0, Atgrdp2 mutants and overexpression lines were grown 7 days in $150 \mathrm{mM} \mathrm{NaCl}$ (Figure 4A).
An evident salt stress sensitivity phenotype was observed in the mutant lines (Figure 4A). The relative primary root growth was slower for Atgrdp2-1 and amiR-1 compared with WT. The relative fresh weight was higher for 35S::AtGRDP2-OE overexpression lines (Figures 4B,D). After salt stress treatments, plantlets were transferred into sterile soil and the survival rate was calculated following a 7 days period of recovery. Plant survival rates indicate that more than $50 \%$ of the overexpression lines recovered 


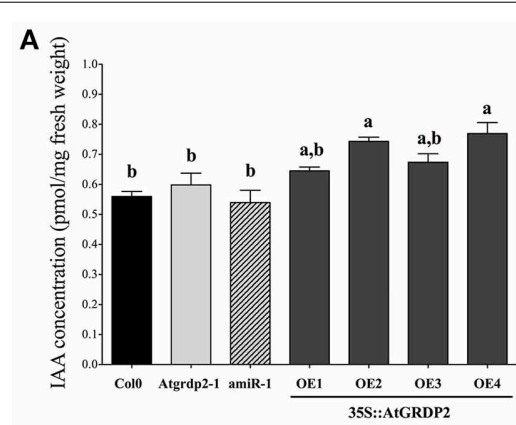

B
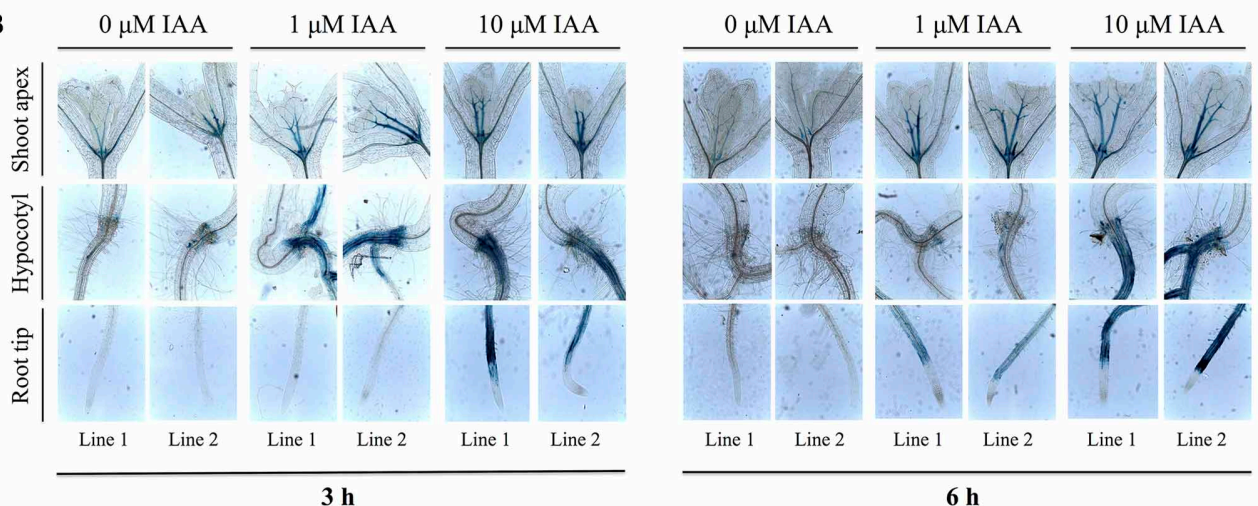

C
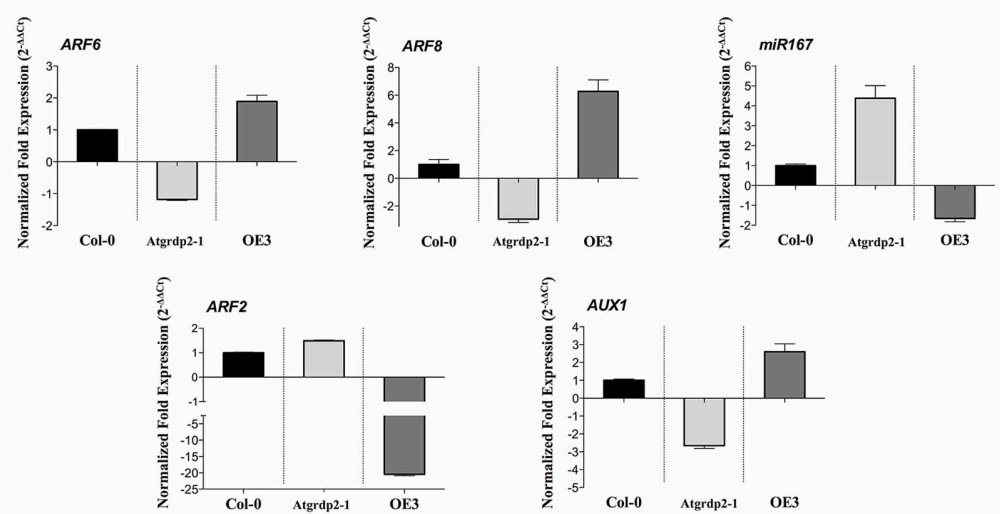

FIGURE 3 | (A) IAA content in Col-0, Atgrdp2-1, amiR-1, and AtGRDP2-OE1, OE2, OE3, and OE4 overexpression lines. Twenty-one days old plants were used for IAA quantification. The experiment was performed on three biological replicates with their respective three technical replicates. Different letters indicate significant differences between samples according to Tukey's multiple comparison tests at $P<0.05$. (B) Modulation of pAtGRDP2::GFP-GUS expression patterns by IAA. Seven day-old seedlings were treated with 0,1 , and $10 \mu \mathrm{M}$ of IAA for 3 and $6 \mathrm{~h}$. Images show representative individuals of two independent lines of pAtGRDP2::GFP-GUS (line 1 and 2). Images were taken on a Leica microscope at 10X magnification and recorded using the Leica Application Suite 3.0.0 software. (C) Expression analysis of auxin-related genes. GRT-PCR was performed in 15 day-old seedlings of Col-0, Atgrdp2-1, and -OE3 overexpression line. Ten seedlings of each line per triplicate were used. For the GRT-PCR analysis it was used SYBR green dye, with the respective technical replicates. Normalized fold change was calculated comparing the target gene expression with a control (Col-0), after normalization to the Arabidopsis UBQ5 gene using the $\left(2^{-\Delta \Delta C t}\right)$ method. In case of ratios lower than 1 , the inverse of the ratio was estimated and the sign was changed. while only $20 \%$ of Atgrdp2-1 was able to survive (Figure 4C). Our data show clear salt stress tolerance in AtGRDP2 overexpression lines.

Furthermore, genes known to be induced by abiotic stress were analyzed by qRT-PCR in 15 day-old Col-0, Atgrdp2-1 mutant and 35S::AtGRDP2-OE3 overexpression lines grown 1 and 3 days under 125 and $150 \mathrm{mM} \mathrm{NaCl}$. Expression levels of the selected genes: Responsive to Desiccation 29B (RD29B), Arabidopsis Early
Methionine-Labeled $6(E M 6 / L E A)$ and ABRE Binding Factor 4 $(A B F 4)$ are shown in Figure 5. These genes are ABA responsive and are mainly induced by stress conditions that involve cellular dehydration. In the 35S::AtGRDP2-OE3 overexpression line, $E M 6, A B F 4$, and $R D 29 B$ genes were up-regulated under salt treatments at both times in comparison to WT plants. In contrast, all the analyzed genes were repressed in Atgrdp2-1 (Figure 5). 
A

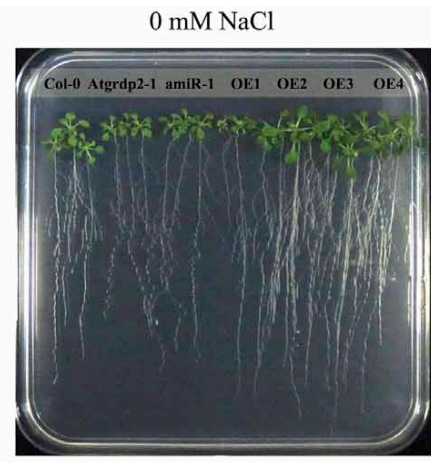

B

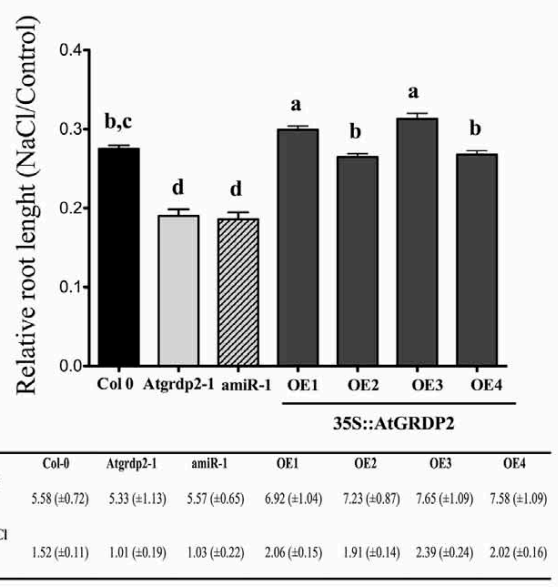

D

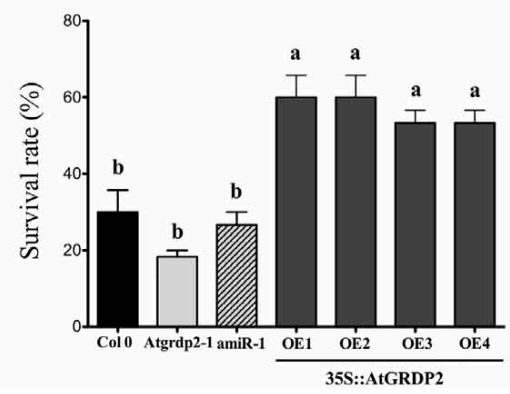

FIGURE 4 | Effect of salt stress on Arabidopsis Col-0, Atgrdp2-1, amiR-1, and AtGRDP2 overexpression lines. (A) Photographs of Arabidopsis (21 day-old) seedlings grown in $0.5 \times \mathrm{MS}$ medium with 0 and $150 \mathrm{mM} \mathrm{NaCl}$ for 7 days (B) Data of primary root length, and relative root length (treated with $150 \mathrm{mM} \mathrm{NaCl} /$ untreated) for each line was represented graphically. (C) Data of fresh weight, and relative fresh

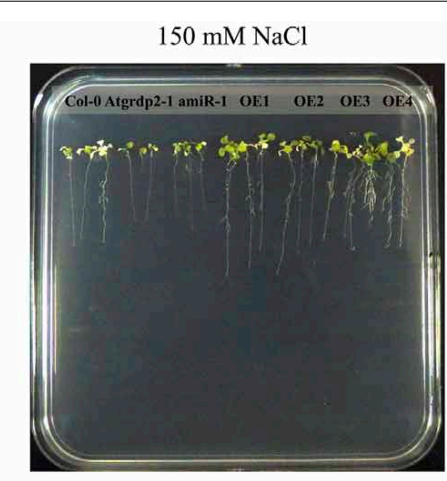

C

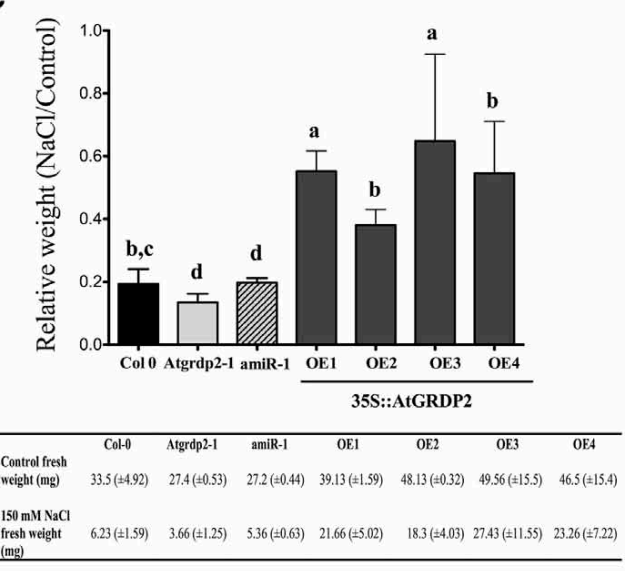

weight (treated with $150 \mathrm{mM} \mathrm{NaCl} /$ untreated) for each line was represented graphically. (D) Survival rate of the Col-0, Atgrdp2-1, amiR-1, and AtGRDP2 overexpression lines after 7 days of salt stress recovery. Data are mean \pm SE $(n=10)$ from three replicates. Different letters indicate significant differences $(P<0.05)$ among lines were explored through Tukey's multiple comparisons tests.

\section{AtGRDP2 OVEREXPRESSION IN LETTUCE ALTERS GROWTH, DEVELOPMENT, AND FLOWERING TIME}

Transgenic lettuce T3 homozygous lines that overexpress the AtGRDP2 gene were generated, and AtGRDP2 expression was estimated by qRT-PCR, observing different levels of AtGRDP2 transcript in the lettuce 35S::AtGRDP2-Ls1, -Ls5, and -Ls9 lines. In WT lettuce, AtGRDP2 expression was not detected as expected (Figure S3E). Overexpression of AtGRDP2 gene positively affects the growth rate of lettuce plants at early stages of development (7 day-old plants; Figure 6A). The 35S::AtGRDP2-Ls5 and $-L s 9$ exhibited faster growth, developed higher fresh weight and longer primary roots than WT plants (Figures 6A-C). In contrast, the 35S::AtGRDP2-Ls1 line, was phenotypically similar to the WT, with no statistical differences in fresh weight and primary root length (Figures 6A-C). The increased growth rate phenotype correlates with AtGRDP2 gene expression in the lettuce transgenic lines (Figure 6A and Figure S3E). After, the transgenic and WT lettuce plantlets were grown in soil. As previously observed, 30 day-old plants of the 35S::AtGRDP2-Ls5 and -Ls9 maintained the highest growth rates, and developed more leaves (Figure 6D). 60 day-old lettuce AtGRDP2 overexpression lines ($L s 1,-L s 5$, and -Ls9) were higher than WT lettuces, reflected in their stem length (Figures 6F-H). No differences were observed in the number of leaves among transgenic and WT at this stage 

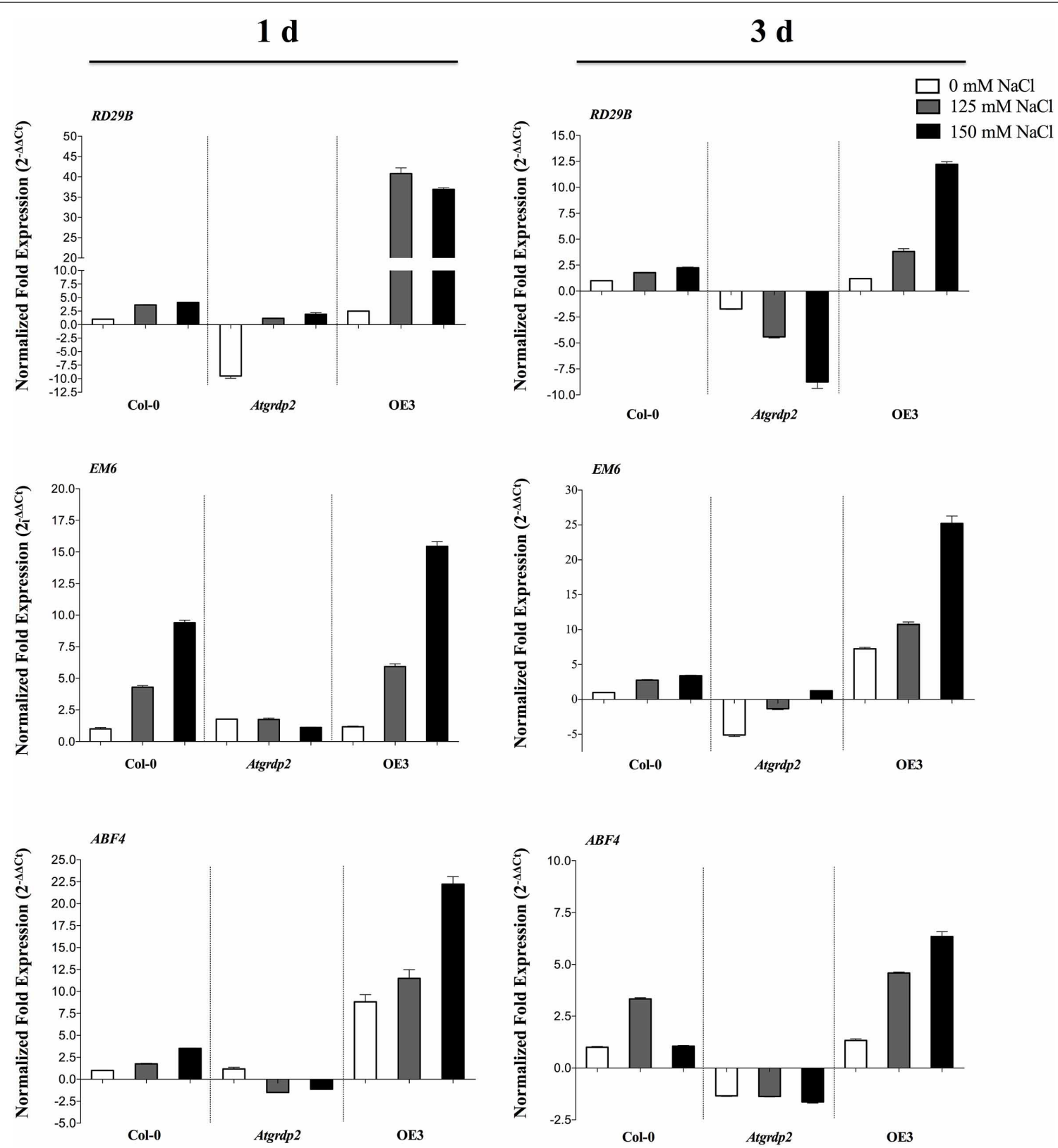

FIGURE 5 | Expression levels of RD29B, EM6, and ABF4 genes in Col-0, Atgrdp2-1, and 35S::AtGRDP2-OE3 overexpression line during salt treatment. Fourteen days old plants grown on 0.5X MS plates were transferred to $0.5 \mathrm{X}$ MS medium containing 0,125 , and $150 \mathrm{mM}$ $\mathrm{NaCl}$, for 1 and 3 days. Ten seedlings of each line per triplicate were used. The expression levels were estimated by qRT-PCR with the

of development (Figures 6F-H). Owing the accelerated growth rate of AtGRDP2 transgenic lettuce lines, flowering time was also analyzed (Figures $\mathbf{6 I}, \mathbf{J}$ ). As expected, inflorescence development was accelerated in the transgenic lines. The 35S::AtGRDP2-Ls5 and $-L s 9$ transgenic lettuce plants flowered 76 days after sowing, 12 days before the WT, while in the 35S::AtGRDP2-Ls1 plants the difference was minor, 2 days before WT flowering time (Figures 6I,J). respective three technical replicates using SYBR green dye. Normalized fold change was calculated comparing the target gene expression (under salt stress) with a control (untreated Col-0), after normalization to the Arabidopsis UBQ5 gene using the $\left(2^{-\Delta \Delta C t}\right)$ method. In case of ratios lower than 1 , the inverse of the ratio was estimated and the sign was changed.

One interesting feature of the lettuce 35S::AtGRDP2 transgenic plants is the presence of light green leaves, in contrast to the dark green color observed in WT lettuce in all the developmental stages analyzed (Figure 6). For this reason, the chlorophyll content was estimated. No significant differences were observed in the total chlorophyll content between WT and transgenic plants (Figure S4). However, the chlorophyll $a / b$ ratio was altered in transgenic plants, due to a higher chlorophyll $b$ content (Figure S4). 

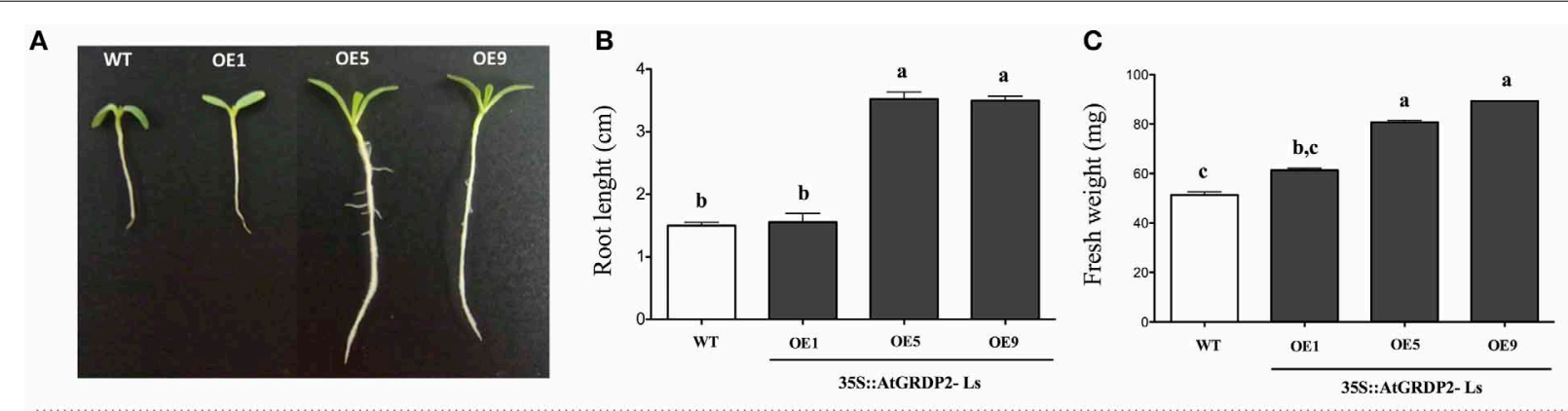

D

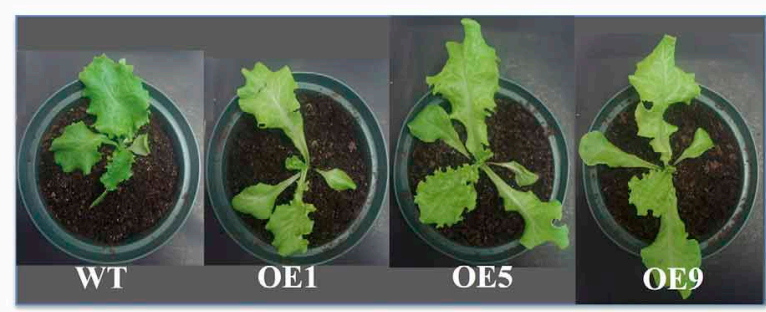

$\mathbf{F}$

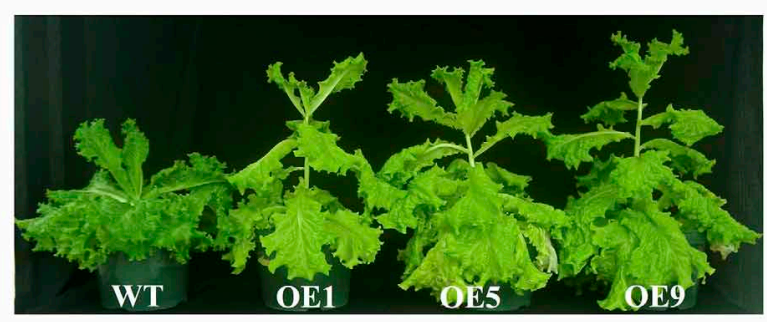

G

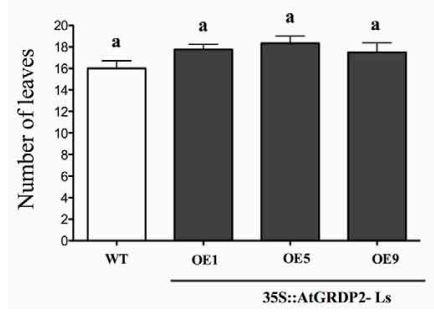

H
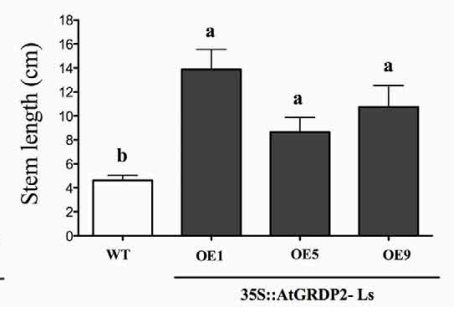

E

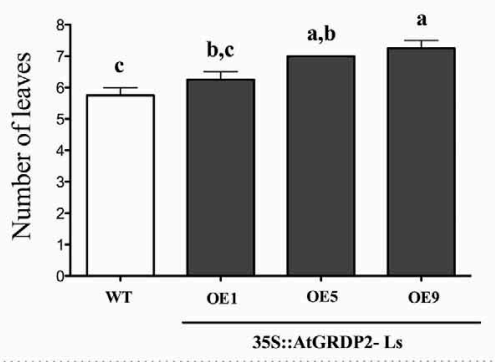

I

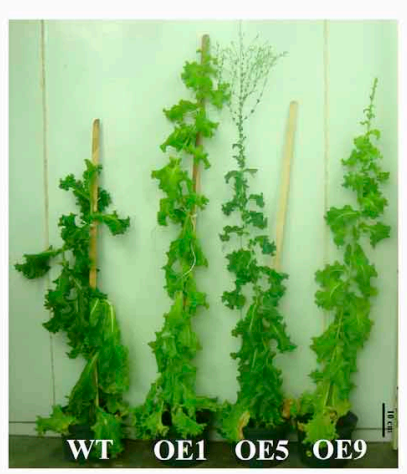

J

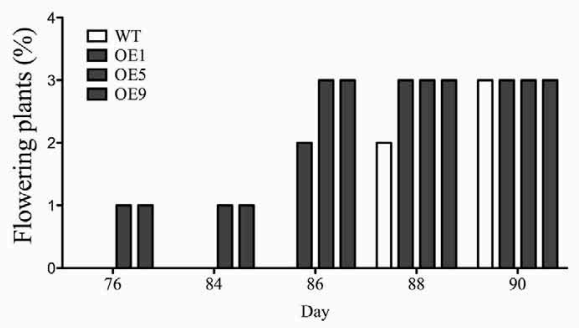

FIGURE 6 | Generation of lettuce transgenic plants overexpressing the Arabidopsis AtGRDP2 gene. (A) Phenotype of 7 day-old WT and transgenic lettuce plants; (B) primary root length, and (C) fresh weight of WT and transgenic lettuce plants was measured. (D) 30 day-old WT and transgenic lettuce plants, (E) the number of leaves in these plants is graphically represented. (F) 60 day-old WT and transgenic lettuce plants;
(G) the number of leaves and (H) stem length are indicated. (I) 90 day-old WT and transgenic lettuce plants; ( $\mathbf{J}$ ) distribution of flowering plants in a period of 15 days is graphically represented. Data was obtained from 9 seedlings of each line, mean $\pm \mathrm{SE}(n=9)$. Different letters indicate significant differences $(P<0.05)$ among lines were explored through Tukey's multiple comparisons tests.
Furthermore, carotenoids content was measured. It was found that transgenic plants diminish their carotenoid content with age, i.e., 90 day-old-transgenic plants show up to $57 \%$ less carotenoids than WT lettuce plants (Figure S4C).

Finally, the response to salinity stress was evaluated in lettuce AtGRDP2 overexpression lines (Figure 7) grown under $150 \mathrm{mM}$ $\mathrm{NaCl}$ for 21 days. At this time, salt tolerance was noticed in the overexpression lines; which had longer roots and increased fresh weight in comparison to WT plants (Figures 7B,C).

\section{DISCUSSION}

In this study, we describe for the first time the AtGRDP2 gene, which belongs to the DUF1399-GRDP family. AtGRDP2 encodes a non-canonical glycine-rich protein of unknown function 


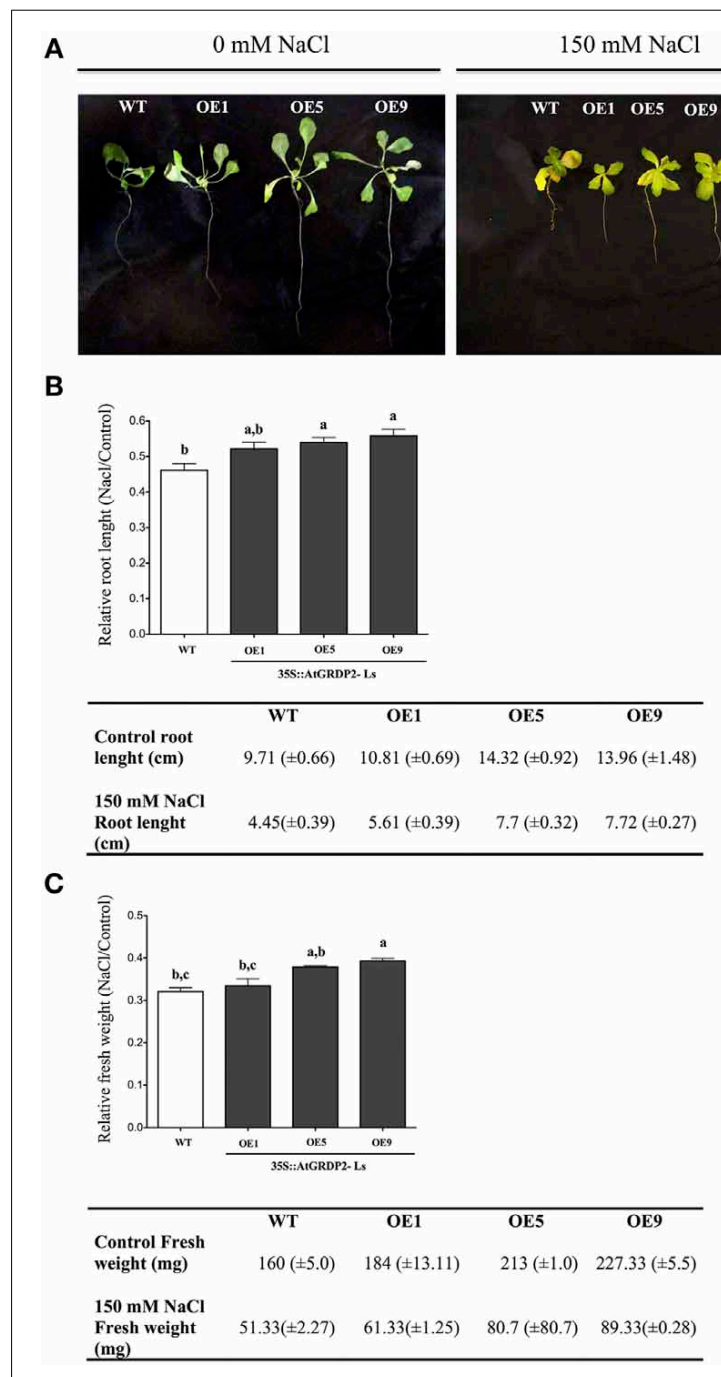

FIGURE 7 | Effect of salt stress on AtGRDP2 lettuce transgenic plants. WT and transgenic lettuce seeds were germinated in MS medium supplemented with 0 and $150 \mathrm{mM} \mathrm{NaCl}$. (A) Photographs of lettuce plants after 21 days of salt stress. (B) Data of primary root length, and relative root length (treated whit $150 \mathrm{mM} \mathrm{NaCl} /$ untreated) for each line was represented graphically. (C) Data of fresh weight, and relative fresh weight (treated whit $150 \mathrm{mM} \mathrm{NaCl} /$ untreated) for each line was represented graphically. Data are obtained for 9 plants for each line, mean $\pm \mathrm{SE}(n=9)$. Different letters indicate significant differences $(P<0.05)$ among lines were explored through Tukey's multiple comparisons tests.

containing a DUF1399 domain, a putative RNA-binding motif and a glycine-rich domain. The three domains present in AtGRDP2 are conserved in other plant orthologous proteins (Figure S1). The Arabidopsis genome has three additional genes encoding proteins with a DUF1399 domain AtGRDP1, At4g37682, and At1g56230 (Rodríguez-Hernández et al., 2014). AtGRDP1 is involved in abiotic stress response and ABA signaling (Rodríguez-Hernández et al., 2014), while the latter are of unknown function. AtGRDP2 and AtGRDP1 seem to be paralogs (Rodríguez-Hernández et al., 2014), and show microsynteny (Kevei et al., 2005). The At4g37682 and At1g56230 proteins do not contain glycine-rich and RNP motifs, and share $46 \%$ and $15 \%$ identity respectively, with AtGRDP2 protein.

The canonical glycine rich proteins contain a high glycine percentage (from 40 to $70 \%$ ), with arranged $(\mathrm{Gly})_{\mathrm{n}} \mathrm{X}$ repetitions (Sachetto-Martins et al., 2000; Mousavi and Hotta, 2005). Besides the canonical GRPs, there are glycine-rich domain proteins (GRDPs), containing a short glycine-rich region. Several transcripts encoding GRDPs have been reported in Eucalyptus (Bocca et al., 2005), and recently our research group reported the Phaseolus vulgaris PvGRDP1 gene, and the Arabidopsis AtGRDP1 gene, which are induced under abiotic stress (Hernández-Lucero et al., 2014; Rodríguez-Hernández et al., 2014). The Arabidopsis AtGRDP2 gene is developmentally regulated, with particularly high mRNA expression levels in buds, flowers, and immature siliques. In accordance, the Arabidopsis microarray database (Arabidopsis eFP Browser, www.bar.utoronto.ca) reports that AtGRDP2 transcript is induced during stages 9, 10, 11, and 12 of flower development (Schmid et al., 2005). The expression of some canonical plant GRPs has been reported in floral organs. The oleosin-like protein GRP17 was identified as a component of the A. thaliana pollen coat required for rapid initiation of pollination (Mayfield and Preuss, 2000). Another characterized GRP, the AtOGB3 that has an oleosin domain, is required for pollen hydration (Mayfield and Preuss, 2000). Transcripts of Arabidopsis GRPs (AtGRP1 and AtGRP2) were found to be abundant in flowers (de Oliveira et al., 1990). These studies suggest that proteins with glycine-rich regions play a role in flower organs development.

We found phenotypes of higher growth rates and development into vigorous plants in Arabidopsis and lettuce AtGRDP2 overexpression lines, in contrast to the Arabidopsis Atgrdp2-1, which show an opposite behavior. The observed phenotypes are in accordance with different levels of AtGRDP2 transcript accumulation, e.g., the 35S::AtGRDP2-OE3 line exhibited the longest primary roots, the highest fresh weight, and the highest transcript levels. In addition, flowering time was estimated under long- and short-day conditions, and it was found that Arabidopsis AtGRDP2 overexpression lines flowered earlier than the parental plants. The Atgrdp2-1 seedlings display a delayed flowering phenotype compared to WT plants. Our data show that AtGRDP2 gene is involved in Arabidopsis growth and development. In accordance, the Arabidopsis AtGenExpress microarray database show AtGRDP2 expression in shoot apex, inflorescence and apical meristems. Some reports related canonical GRPs to developmental processes. The vacuole-located glycine-rich protein AtGRP5 plays a role in organ growth possibly by promoting cell elongation processes (Mangeon et al., 2009). AtGRP5 overexpression generated plants with longer roots and enhanced elongation of the inflorescence axis. Likewise, AtGRP7 (an RNA-binding protein) promotes floral transition in Arabidopsis through the autonomous pathway (Streitner et al., 2008).

Interestingly, the accelerated growth phenotype was noticed in both Arabidopsis and lettuce transgenic plants at different stages of development (seedling stage, vegetative, and reproductive growth). Deregulation of AtGRDP2 gene levels affects growth and development, possibly due to hormonal changes. We found that Arabidopsis AtGRDP2 overexpression lines show increased 
levels of the auxin indole-3-acetic acid (IAA). Unexpectedly, the Atgrdp2-1 maintain similar levels of IAA as the WT. It might be that the other genes of the Arabidopsis DUF1399 family, mainly the AtGRDP1 paralog have functional redundancy with AtGRDP2. Auxins control several fundamental aspects of the plant development, such as cell division, cell expansion, pattern formation, root development, and apical dominance, and also environmental responses such as photo- and gravitropism (Berleth and Sachs, 2001; Woodward and Bartel, 2005). Microarray data published by Goda et al. (2004) revealed that the AtGRDP2 belongs to a group of genes specifically regulated by IAA. Consistent with these observations, we found auxin response elements (ARF binding sites) in the AtGRDP2 promoter (Figure S5), and IAA treatments of AtGRDP2::GFP-GUS-1 seedlings show increased GUS expression in the root-hypocotyl junction and in the root differentiation zone.

Furthermore, we evaluated the expression of $A R F$ transcription factors in Col-0, Atgrdp2-1 and 35S::AtGRDP2-OE3 overexpression lines. ARFs bind to auxin response promoter elements and mediate auxin dependent gene expression (Guilfoyle and Hagen, 2007). The lack and constitutive overexpression of AtGRDP2 alters the expression of ARF6 and ARF8 regulators of floral development, showing an induction of both genes in 35S::AtGRDP2-OE3 line, and a repression in the Atgrdp2-1. $A R F 6$ and $A R F 8$ are fined tuned by $m i R 167$, and the overexpression of $m i R 167$ mimics arf6/arf8 phenotypes of flowering delay (Wu et al., 2006; Rubio-Somoza and Weigel, 2013). miR167 is induced in Atgrdp2-1 and repressed in 35S::AtGRDP2-OE3 lines. miR167, ARF6, and ARF8 form part of a regulatory network that is essential for flower organ maturation and root development in Arabidopsis (Curaba et al., 2014). The expression patterns observed for miR167, ARF6, and ARF8 might explain the phenotypes of delayed or accelerated flowering observed in the Atgrdp2-1 mutant and overexpression lines. Another important auxin-regulated gene is $A U X 1$, which encodes an auxin influx facilitator protein involved in polar auxin transport (Kramer and Bennett, 2006; Paponov et al., 2008). In the 35S::AtGRDP2-OE3 overexpression line, higher $A U X 1$ transcript levels are detected, suggesting a major auxin influx in these lines.

Recent studies refer a connection between auxin response and abiotic stress, by crosstalk with ABA signaling (Du et al., 2012, 2013). We observed that the 35S::AtGRDP2 overexpression lines with increased auxin levels are also more tolerant to salt stress. Conversely, Atgrdp2-1 lines were susceptible to salt stress, and most mutant lines were unable to survive after stress treatments. In accordance, microarray data show that the AtGRDP2 gene is induced by salt stress in Arabidopsis roots (Ma et al., 2006). Recently, we reported that the common bean PvGRDP1 gene, orthologous to Arabidopsis AtGRDP2 gene, was induced in leaves by salt stress at 2 and 5 days, but was downregulated in stems after 2 days of treatment (Hernández-Lucero et al., 2014). The expression pattern of some stress marker genes was monitored between the Atgrdp2-1 and 35S::AtGRDP2-OE3 overexpression lines under salt stress. We selected the transcription factor $A B F 4$ (ABRE Binding Factor 4), Em6 (LEA-1), and $R D 29 B$ (Responsive to Desiccation 29B) genes, which are induced by diverse abiotic stresses including salinity (Uno et al., 2000;
Kang et al., 2002; Hundertmark and Hincha, 2008). Our results showed that salt treatment down-regulated most marker genes in the Atgrdp2-1 line, in contrast to the increased expression noticed in the 35S::AtGRDP2-OE3 line at 1 and 3 days of salt stress. Shi et al. (2014) propose that auxin might contribute in the positive regulation of drought stress resistance, through regulation of root architecture, ABA-responsive genes expression, ROS metabolism, and metabolic homeostasis. They found that endogenous and exogenous auxin positively modulated the expression levels of multiple abiotic stress-related genes such as $R A B 18, R D 22, R D 29 A, R D 29 B, D R E B 2 A$, and DREB2B. These data are in accordance with our observations in AtGRDP2 overexpression lines that accumulate IAA, express higher levels of stress responsive genes, and become salt stress tolerant. As well, down regulation of ARF2 in 35S::AtGRDP2-OE3 line might be related to stress tolerance. On the other hand, a slight induction of ARF2 gene was observed in Atgrdp2-1 background. arf2 mutants have a delay in leaf senescence and are more resistant to oxidative stress (Lim et al., 2010).

It has been reported that $A t G R D P 1$ gene, paralog to AtGRDP2, is modulated to several abiotic stress, including salt treatment. The Atgrdp1 mutant line was sensible to salt and osmotic stress during germination and cotyledon development, whereas 35S::AtGRDP1 over-expressing lines resulted in increased tolerance to abiotic stress. In addition, 35S::AtGRDP1 over-expressing lines were more resistant to ABA, resembling to well-known ABI phenotype, whereas disruption of the AtGRDP1 gene resulted in ABA hypersensitivity (Rodríguez-Hernández et al., 2014).

AtGRDP2 transgenic lettuce lines showed several interesting phenotypes, i.e., plants grow faster, tolerate salt stress, have lower content of carotenoids, and the chlorophyll $a / b$ ratio is altered. Recently, Du et al. (2013) proposed that the balance of carotenoid, ABA and auxin homeostasis is critical for rice development and stress responses. Since lettuce is a high-value leafy vegetable grown commercially worldwide, transformed lines might have implications in the development of improved phenotypes given the high demand and the susceptibility of this crop to dehydration and salt stress (Martinez-Gonzalez et al., 2011; Kerbiriou et al., 2013; Kim et al., 2013).

It has been reported that canonical GRPs containing an RRMGRPs can be modulated under abiotic stress (Kang et al., 2013; Yang et al., 2014). Such is the case of the Arabidopsis glycinerich RNA-binding protein 2 (GRP2) that is involved in salt and cold stress tolerance during germination and seedling growth (Kim et al., 2007). Transgenic tobacco plants overexpressing the Limonium bicolor GRP gene are tolerant to salt stress, possibly due to increased superoxide dismutase and catalase activities and proline content (Wang et al., 2012). As well, overexpression of AtGRP2 and AtGRP7 in rice confers drought stress tolerance (Yang et al., 2014).

Herein, we present fast-growing Arabidopsis and lettuce transgenic plants that overexpress the AtGRDP2 gene. AtGRDP2 belongs to a novel family of Arabidopsis proteins containing the DUF1399 domain. AtGRDP2 gene is developmentally regulated showing particular expression patterns in Arabidopsis floral organs. It was found that AtGRDP2 is an auxin-regulated gene. Deregulation of AtGRDP2 in Arabidopsis mutant and 
overexpression lines affects the expression of key regulators of floral development ( $A R F 6, A R F 8$, and $m i R 167$ ), leading to delay or acceleration of flowering in Arabidopsis. Increased auxin levels in AtGRDP2 overexpression lines were correlated with salt stress tolerance and up-regulation of markers of stress response. Our data reveal an important role for AtGRDP2 in plant growth and development, possibly through an auxin dependent mechanism.

\section{ACKNOWLEDGMENT}

This work was financially supported by CONACYT (Investigación Ciencia Básica 2008-103106) funding.

\section{SUPPLEMENTARY MATERIAL}

The Supplementary Material for this article can be found online at: http://www.frontiersin.org/journal/10.3389/fpls.2014.00782/ abstract

Figure S1 | The Arabidopsis Glycine Rich Domain Protein 2 (AtGRDP2). (A) Schematic representation of AtGRDP2 domains: DUF1399, RNP-1, and GRD. The amino acid sequence of each domain is indicated within rectangles. (B) Unrooted phylogenetic tree of AtGRDP2 orthologous proteins and Arabidopsis proteins containing the DUF1399 domain (At2g22660, At1g56230, and At4g37682). The phylogenetic tree was created by the Neighbor Joining method of the PHYLIP 3.67 package (Felsenstein, 1989). Bootstrap support values out of 1000 pseudoreplicates of the data set and values are provided as percentages at the corresponding nodes when $>50 \%$. Phytozome accession numbers are as follows: Al, (Arabidopsis lyrata, 353047); Cr, (Capsella rubella, Carubv10004166m); Th, (Thellungiella hallophila, Thhalv10024448m); Br, (Brassica rapa, Bra010619); Cp (Carica papaya, 755.1); Ls (Linum usitatissimum, Lus 10019239); Pt (Populus trichocarpa,

POPTR_0015s04140.1); Me (Manihot esculenta, cassava4.1_002413m); Rc (Ricinus communis, 28333.m000558); Eg (Eucalyptus grandis, Eucgr.100602.1); Ppa (Prunus persica, ppa001356m); Mt (Medicago truncatula, Medtr5g030890.1); Pv, (Phaseolus vulgaris, Phvulv091027346m); Gm (Glycine max, Glyma01g02400); Cc (Citrus clementina, clementine0.9_002162m); Cs (Citrus sinensis, orange1.1g002907m); Ac (Aquilegia coerulea, Aquca_010_0041.1); Mg (Mimulus guttatus, mgv1a001553m); Os (Oryza sativa, Os11g40590); Bd (Brachypodium distachyon, Bradi4g13267); Si (Setaria italica, Si025845m); $\mathrm{Sb}$ (Sorghum bicolor, Sb05g025070); and Zm (Zea mays,

GRMZM26358827_T01). (C) Schematic representation of the predicted A. thaliana DUF1399 proteins, AtGRDP1 (At2g22660), AtGRDP2

(At4g37900), At1g56230, and At4g37682. In the case of the AtGRDP1 and AtGDRP2 proteins, the RNP-1 motif and the glycine-rich domain (GRD) are indicated.

\section{Figure S2 | Multiple sequence alignment of AtGRDP2 plant orthologous} proteins. Identical residues in the seven proteins are shown in black, and conserved substitutions are in gray. The conserved regions are underlined: the Domain of Unknown Function 1399 (DUF1399), the putative RNA binding motif -1 (RNP-1) and the glycine-rich domain (GRD). Pv (P. vulgaris, Phvulv091027346m); Gm (G. max, Glyma01g02400); Br (B. rapa, Bra010619); Th (T. hallophila, Thhalv10024448m); Cr (C. rubella, Carubv10004166m); Al (A. lyrata, 353047); At (A. thaliana, At4g37900).

Figure S3 | Gene structure and expression of AtGRDP2 gene in Col-0, Atgrdp2-1, amiR-1 knockdown, and 35S::AtGRDP2 over-expression lines. (A) Schematic representation of T-DNA insertion site (black triangle) at fourth exon in the Sail_387D04 mutant line. Exons are shown in black rectangles, and introns in solid lines. RT-PCR analysis of AtGRDP2 gene in control and Atgrdp2-1 mutant plants; Actin 8 gene was used as loading control. (B) Schematic representation of the pAmiR-AtGRDP2 vector. LB, left border for T-DNA integration; CaMV 35S, cauliflower mosaic virus $35 \mathrm{~S}$ promoter; attB1 and attB2 sites for recombination; amiR-AtGRDP2,

A. thaliana GRDP2 artificial microRNA; 3'-OCS, octopine synthase terminator; bar gene as herbicide resistance marker (BASTA); RB, right border for T-DNA integration. qRT-PCR expression levels of AtGRDP2 on three independent amiR-AtGRDP2 lines. (C) Schematic representation of the 35S::AtGRDP2 construct in pMDC32 binary vector. RB, right border for T-DNA integration; $2 \times 35$ S, cauliflower mosaic virus 35S promoter; attB1 and attB2 sites for recombination; AtGRDP2, A. thaliana GRDP2 CDNA; nos T, nopaline synthase terminator region; HPTII, hygromycin resistance gene; LB, left border for T-DNA integration. (D) qRT-PCR expression levels of AtGRDP2 in the Arabidopsis overexpression lines is represented as normalized fold change, and was calculated comparing the target gene expression with a control (Col-0), after normalization to the Arabidopsis UBQ5 gene using the $\left(2^{-\Delta \Delta C t}\right)$ method. (E) Relative gene expression levels of $A t G R D P 2$ gene in transgenic lettuce are presented as $2^{-\triangle \mathrm{Ct}}$, where $\triangle \mathrm{Ct}=\mathrm{Ct}_{A t G R D P 2}-\mathrm{Ct}_{\angle s \cup B Q 5}$. Bars represent mean $\pm \mathrm{SE}$ $(n=3)$ of two experimental replicates.

Figure S4 | Chlorophyll and carotenoids content in WT and AtGRDP2 transgenic lettuce lines. Lettuce plants of 30 (A), 60 (B) and, 90 day-old (C), were analyzed for chlorophyll a and b, and carotenoids content. The relation of chlorophyll a/b was calculated. Data are mean \pm SE $(n=4)$ with the respective three technical replicates. Letters indicate significant differences between samples according to Tukey's multiple comparison tests at $P<0.05$.

Figure S5 | Putative auxin-responsive elements on AtGRDP2 promoter by using PLACE analysis. Promoter of AtGRDP2 (2000 bp) was analyzed in the PLACE database. In the schematic representation, ARFAT boxes (gray), and SURECOREATSULTR11 boxes (black), and its localization in bp are indicated.

\section{REFERENCES}

Alonso, J. M., Stepanova, A. N., Leisse, T. J., Kim C. J., Chen, H., Shinn, P., et al. (2003). Genome-wide insertional mutagenesis of Arabidopsis thaliana. Science 301, 653-657. doi: 10.1126/science.1086391

Bailey, T. L., and Elkan, C. (1994). "Fitting a mixture model by expectation maximization to discover motifs in biopolymers" in Proceedings of the Second International Conference on Intelligent Systems for Molecular Biology (Menlo Park, CA: AAAI Press), 28-36.

Berleth, T., and Sachs, T. (2001). Plant morphogenesis: long-distance coordination and local patterning. Curr. Opin. Plant Biol. 4, 57-62. doi: 10.1016/S13695266(00)00136-9

Bocca, S. N., Magioli, C., Mangeon, A., Junqueira, R. M., Cardeal, V., and Margis, R. (2005). Survey of glycine rich proteins (GRPs) in the Eucalyptus expressed sequence tag database (ForEST). Gen. Mol. Biol. 28, 608-624. doi: $10.1590 /$ S1415-47572005000400016

Clough, S. J., and Bent, A. F. (1998). Floral dip: a simplified method for Agrobacterium-mediated transformation of Arabidopsis thaliana. Plant J. 16, 735-743. doi: 10.1046/j.1365-313x.1998.00343.x

Condit, C. M. (1993). Developmental expression and localization of petunia glycine-rich protein 1. Plant Cell 5, 277-288. doi: 10.1105/tpc.5.3.277

Curaba, J., Singh, M. B., and Bhalla, P. L. (2014). miRNAs in the crosstalk between phytohormone signaling pathways. J. Exp. Bot. 65, 1425-1438. doi: 10.1093/jxb/eru002

Curtis, I. S., Power, J. B., Blackhall, N. W., de Laat, A. M. M., and Davey, M. R. (1994). Genotype-independent transformation of lettuce using Agrobacterium tumefaciens. J. Exp. Bot. 45, 1441-1449. doi: 10.1093/jxb/45.10.1441 
de Oliveira, D. E., Seurinck, J., Inzé, D., Van Montagu, M., and Botterman, J. (1990). Differential expression of five Arabidopsis genes encoding glycine-rich proteins. Plant Cell 2, 427-436. doi: 10.1105/tpc.2.5.427

Du, H., Wu, N., Chang, Y., Li, X., Xiao, J., and Xiong, L. (2013). Carotenoid deficiency impairs ABA and IAA biosynthesis and differentially affects drought and cold tolerance in rice. Plant Mol. Biol. 83, 475-488. doi: 10.1007/s11103-0130103-7

Du, H., Wu, N., Fu, J., Wang, S., Li, X., Xiao, J., et al. (2012). A GH3 family member, $\mathrm{Os} G H 3-2$, modulates auxin and abscisic acid levels and differentially affects drought and cold tolerance in rice. J. Exp. Bot. 63, 6467-6480. doi: $10.1093 / \mathrm{jxb} / \mathrm{ers} 300$

Felsenstein, J. (1989). PHYLIP-Phylogeny Inference Package (version 3.2). Cladistics 5, 164-166.

Goda, H., Sawa, S., Asami, T., Fujioka, S., Shimada, Y., and Yoshida, S. (2004). Comprehensive comparison of auxin-regulated and brassinosteroid-regulated genes in Arabidopsis. Plant Physiol. 134, 1555-1573. doi: 10.1104/pp.103. 034736

Guilfoyle, T. J., and Hagen, G. (2007). Auxin response factors. Curr. Opin. Plant Biol. 10, 453-460. doi: 10.1016/j.pbi.2007.08.014

Hendry, G. A. F., and Price, A. H. (1993). "Stress indicators: chlorophylls and carotenoids" in Methods in Comparative Plant Ecology, eds G. A. F. Hendry and J. P. Grime (London: Chapman \& Hall), 148-152.

Hernández-Lucero, E., Rodriguez-Hernandez, A. A., Ortega-Amaro, M. A., and Jimenez-Bremont, J. F. (2014). Differential expression of genes for Ttolerance to salt stress in common bean (Phaseolus vulgaris L.). Plant Mol. Biol. Rep. 32, 318-327. doi: 10.1007/s11105-013-0642-8

Hundertmark, M., and Hincha, D. K. (2008). LEA (late embryogenesis abundant) proteins and their encoding genes in Arabidopsis thaliana. BMC Genomics 9:118. doi: 10.1186/1471-2164-9-118

Kang, H., Park, S. J., and Kwak, K. J. (2013). Plant RNA chaperones in stress response, Trends Plant Sci. 18, 100-106. doi: 10.1016/j.tplants.2012.08.004

Kang, J. Y., Choi, H. I., Im, M. Y., and Kim, S. Y. (2002). Arabidopsis basic leucine zipper proteins that mediate stress-responsive abscisic acid signaling. Plant Cell 14, 343-357. doi: 10.1105/tpc.010362

Karimi, M., Inze, D., and Depicker, A. (2002). GATEWAY vectors for Agrobacterium-mediated plant transformation. Trends Plant Sci. 7, 193-195. doi: 10.1016/S1360-1385(02)02251-3

Keller, B., Sauer, N., and Lamb, C. J. (1988). Glycine-rich cell wall proteins in bean: gene structure and association of the protein with the vascular system. EMBO J. 7, 3625-3633.

Kerbiriou, P. J., Stomph, T. J., Van Der Putten, P. E. L., Van Bueren, E. T. L., and Struik, P. C. (2013). Shoot growth, root growth and resource capture under limiting water and $\mathrm{N}$ supply for two cultivars of lettuce (Lactuca sativa L.). Plant Soil 371, 281-297. doi: 10.1007/s11104-013-1672-6

Kevei, Z., Seres, A., Kereszt, A., Kalo, P., Kiss, P., Tóth, G., et al. (2005). Significant microsynteny with new evolutionary highlights is detected between Arabidopsis and legume model plants despite the lack of macrosynteny. Mol. Genet. Genomics 274, 644-657. doi: 10.1007/s00438-005-0057-9

Kim, D. H., Xu, Z. Y., and Hwang, I. (2013). AtHSP17.8 overexpression in transgenic lettuce gives rise to dehydration and salt stress resistance phenotypes through modulation of ABA-mediated signaling. Plant Cell Rep. 32, 1953-1963. doi: 10.1007/s00299-013-1506-2

Kim, J. Y., Park, S. J., Jang, B., Jung, C.-H., Ahn, S. J., Goh, C.-H., et al. (2007). Functional characterization of a glycine-rich RNA-binding protein2 in Arabidopsis thaliana under abiotic stress conditions. Plant J. 50, 439-451. doi: 10.1111/j.1365-313X.2007.03057.x

Kramer, E. M., and Bennett, M. J. (2006). Auxin transport: a field in flux. Trends Plant Sci. 11, 382-386. doi: 10.1016/j.tplants.2006.06.002

Lim, P. O., Lee, I. C., Kim, J., Kim, H. J., Ryu, J. S., Woo, H. R., et al. (2010). Auxin response factor 2 (ARF2) plays a major role in regulating auxin-mediated leaf longevity. J. Exp. Bot. 61, 1419-1430. doi: 10.1093/jxb/ erq010

Livak, K. J., and Schmittgen, T. D. (2001). Analysis of relative gene expression data using real-time quantitative PCR and the 2 [-Delta Delta C(T)] method. Methods 25, 402-408. doi: 10.1006/meth.2001.1262

Long, R., Yang, Q., Kang, J., Zhang, T., Wang, H., Li, M., et al. (2013). Overexpression of a novel salt stress-induced glycine-rich protein gene from alfalfa causes salt and ABA sensitivity in Arabidopsis. Plant Cell Rep. 32, 1289-1298. doi: 10.1007/s00299-013-1443-0
Lorković, Z. J., and Barta, A. (2002). Genomic analysis: RNA recognition motif (RRM) and $\mathrm{K}$ homology $(\mathrm{KH})$ domain RNA-binding proteins from the flowering plant Arabidopsis thaliana. Nucleic Acids Res. 30, 623-635. doi: 10.1093/nar/30.3.623

Ma, S., Gong, Q., and Bohnert, H. J. (2006). Dissecting salt stress pathways. J. Exp. Bot. 57, 1097-1107. doi: 10.1093/jxb/erj098

Mangeon, A., Junqueira, R. M., and Sachetto-Martins, G. (2010). Functional diversity of the plant glycine-rich proteins superfamily. Plant Signal. Behav. 5, 99-104. doi: 10.4161/psb.5.2.10336

Mangeon, A., Magioli, C., Menezes-Salgueiro, A. D., Cardeal, V., de Oliveira, C., and Galvao, V. C. (2009). AtGRP5, a vacuole-located glycine-rich protein involved in cell elongation. Planta 230, 253-265. doi: 10.1007/s00425-0090940-4

Martinez-Gonzalez, L., Rosales-Mendoza, S., Soria-Guerra, R. E., Moreno-Fierros, L., López-Revilla, R., Korban, S. S., et al. (2011). Oral immunization with a lettuce-derived Escherichia coli heat-labile toxin B subunit induces neutralizing antibodies in mice. PCTOC 107, 441-449. doi: 10.1007/s11240-0119994-7

Mayfield, J. A., and Preuss, D. (2000). Rapid initiation of Arabidopsis pollination requires the oleosin-domain protein GRP17. Nat. Cell Biol. 2, 128-130. doi: $10.1038 / 35000084$

Mousavi, A., and Hotta, Y. (2005). Glycine-rich proteins: a class of novel proteins. Appl. Biochem. Biotechnol. 120, 169-174. doi: 10.1385/ABAB:120:3:169

Murashige, T., and Skoog, F. (1962). A revised medium for rapid growth and bio assays with tobacco tissue cultures. Plant Physiol. 15, 473-497. doi: 10.1111/j.1399-3054.1962.tb08052.x

Notredame, C., Higgins, D. G., and Heringa, J. (2000). T-coffee: a novel method for fast and accurate multiple sequence alignment. J. Mol. Biol. 302, 205-217. doi: 10.1006/jmbi.2000.4042

Ortega-Amaro, M. A., Rodriguez-Kessler, M., Becerra-Flora, A., and JimenezBremont, J. F. (2012). Modulation of Arabidopsis CYCB1 expression patterns by polyamines and salt stress. Acta Physiol. Plant. 34, 461-469. doi: 10.1007/s11738-011-0842-5

Paponov, I. A., Paponov, M., Teale, W., Menges, M., Chakrabortee, S., Murray, J. A., et al. (2008). Comprehensive transcriptome analysis of auxin responses in Arabidopsis. Mol. Plant 1, 321-337. doi: 10.1093/mp/ssm021

Reddy, A. S. N., and Poovaiah, B. W. (1987). Accumulation of a glycine rich protein in auxin-deprived strawberry fruits. Biochem. Biophys. Res. Commun. 147, 885-891. doi: 10.1016/S0006-291X(87)80153-5

Rodríguez-Hernández, A. A., Ortega-Amaro, M. A., Delgado-Sanchez, P., Salinas, J., and Jimenez-Bremont, J. F. (2014). AtGRDP1 gene encoding a Glycine-Rich Domain protein is involved in germination and responds to ABA signaling. Plant Mol. Biol. Rep. 32, 303-616. doi: 10.1007/s11105-014-0714-4

Roeder, A. H. K., and Yanofsky, M. F. (2006). "Fruit development in Arabidopsis," in The Arabidopsis Book, eds S. C. Somerville and E. M. Myerowitz (Rockville: American Society of Plant Biologist), 1-50.

Rubio-Somoza, I., and Weigel, D. (2013). Coordination of flower maturation by a regulatory circuit of three microRNAs. PLoS Genet. 9:e1003374. doi: 10.1371/journal.pgen.1003374

Ryser, U., Schorderet, M., Zhao, G.-F., Studer, D., Ruel, K., Hauf, G., et al. (1997). Structural cell-wall proteins in protoxylem development: evidence for a repair process mediated by a glycine-rich protein. Plant J. 12, 97-111. doi: 10.1046/j.1365-313X.1997.12010097.x

Sachetto-Martins, G., Franco, L. O., and de Oliveira, D. E. (2000). Plant glycinerich proteins: a family or just proteins with a common motif? Biochem. Biophys. Acta 1492, 1-14. doi: 10.1016/S0167-4781(00)00064-6

Schmid, M., Davison, T. S., Henz, S. R., Pape, U. J., Demar, M., Vingron, M., et al. (2005). A gene expression map of Arabidopsis development. Nat. Genet. 37, 501-506. doi: 10.1038/ng1543

Schwab, R., Ossowski, S., Riester, M., Warthmann, N., and Weigel, D. (2006). Highly Specific gene silencing by artificial microRNAs in Arabidopsis. Plant Cell 18, 1121-1133. doi: 10.1105/tpc.105.039834

Shi, H., Chen, L., Ye, T., Liu, X., Kejian Ding, K., and Chan, Z. (2014). Modulation of auxin content in Arabidopsis confers improved drought stress resistance. Plant Physiol. Biochem. 82, 209-217. doi: 10.1016/j.plaphy.2014.06.008

Streitner, C., Danisman, S., Wehrle, F., Schoning, J. C., Alfano, J. R., and Staiger, D. (2008). The small glycine-rich RNA binding protein AtGRP7 promotes floral transition in Arabidopsis thaliana. Plant J. 56, 239-250. doi: 10.1111/j.1365313X.2008.03591.x 
Tamura, K., Peterson, D., Peterson, N., Stecher, G., Nei, M., and Kumar, S. (2011). MEGA5: molecular evolutionary genetics analysis using maximum likelihood, evolutionary distance, and maximum parsimony methods. Mol. Biol. Evol. 28, 2731. doi: 10.1093/molbev/msr121

Uno, Y., Furihata, T., Abe, H., Yoshida, R., Shinozaki, K., and Yamaguchi-Shinozaki, K. (2000). Arabidopsis basic leucine zipper transcription factors involved in an abscisic acid-dependent signal transduction pathway under drought and high-salinity conditions. Proc. Natl. Acad. Sci. U.S.A. 97, 11632-11637. doi: 10.1073/pnas.190309197

Urbez, C., Cercós, M., Perez-Amador, M. A., and Juan Carbonell, J. (2006). Expression of PsGRP1, a novel glycine rich protein gene of Pisum sativum, is induced in developing fruit and seed and by ABA in pistil and root. Planta 223, 1292-1302. doi: 10.1007/s00425-005-0178-8

Veerassamy, S., Smith, A., and Tillier, E. R. M. (2003). A transition probability model for amino acid substitutions from blocks. J. Comput. Biol. 10, 997-1010. doi: 10.1089/106652703322756195

Wang, C., Zhang, D. W., Wang, Y. C., Zheng, L., and Yang, C. P. (2012). A glycinerich RNA-binding protein can mediate physiological responses in transgenic plants under salt stress. Mol. Biol. Rep. 39, 1047-1053. doi: 10.1007/s11033-0110830-2

Woodward, A. W., and Bartel, B. (2005). Auxin: regulation, action, and interaction. Ann. Bot. 95, 707-735. doi: 10.1093/aob/mci083

Wu, M.-F., Tian, Q., and Reed, J. W. (2006). Arabidopsis microRNA167 controls patterns of ARF6 and ARF8 expression, and regulates both female and male reproduction. Development 133, 4211-4218. doi: 10.1242/dev. 02602
Yang, D. H., Kwak, K. J., Kim, M. K., Park, S. J., Yang, K.-Y., and Kang, H. (2014). Expression of Arabidopsis glycine-rich RNA-binding protein AtGRP2 orAtGRP7 improves grain yield of rice (Oryza sativa) under drought stress conditions. Plant Sci. 214, 106-112. doi: 10.1016/j.plantsci.2013.10.006

Conflict of Interest Statement: The authors declare that the research was conducted in the absence of any commercial or financial relationships that could be construed as a potential conflict of interest.

Received: 03 September 2014; accepted: 17 December 2014; published online: 20 January 2015.

Citation: Ortega-Amaro MA, Rodríguez-Hernández AA, Rodríguez-Kessler $M$, Hernández-Lucero E, Rosales-Mendoza S, Ibáñez-Salazar A, Delgado-Sánchez P and Jiménez-Bremont JF (2015) Overexpression of AtGRDP2, a novel glycine-rich domain protein, accelerates plant growth and improves stress tolerance. Front. Plant Sci. 5:782. doi: $10.3389 / \mathrm{fpls} .2014 .00782$

This article was submitted to Plant Physiology, a section of the journal Frontiers in Plant Science.

Copyright (C) 2015 Ortega-Amaro, Rodríguez-Hernández, Rodríguez-Kessler, Hernández-Lucero, Rosales-Mendoza, Ibáñez-Salazar, Delgado-Sánchez and Jiménez-Bremont. This is an open-access article distributed under the terms of the Creative Commons Attribution License (CC BY). The use, distribution or reproduction in other forums is permitted, provided the original author(s) or licensor are credited and that the original publication in this journal is cited, in accordance with accepted academic practice. No use, distribution or reproduction is permitted which does not comply with these terms. 